\title{
SIDI BULGAYZ, PROTECTOR DE LOS MORISCOS EXILIADOS EN TÚNEZ (s. XVII). NUEVOS DOCUMENTOS TRADUCIDOS Y ESTUDIADOS*
}

\author{
Mikel de Epalza ${ }^{1}$ \\ Universidad de Alicante
}

Con ocasión de este conjunto de trabajos en homenaje al Profesor Leonard Patrick Harvey, de la Universidad de Londres y de Oxford, quisiera presentar y estudiar, en castellano, cuatro textos sobre la instalación en Túnez de los moriscos o musulmanes hispanos, expulsados de España a principios del siglo XVII. Es una forma de recordar la primera de las colaboraciones científicas que pedí al Prof. Harvey, hace unos 30 años, y que él me ofreció con su conocida generosidad, para un libro colectivo que trataba precisamente de los moriscos o andalusíes en Tunicia ${ }^{2}$. Son un testimonio más de una colaboración de calidad, durante varias décadas ${ }^{3}$.

\section{PRESENTACIÓN GENERAL DEL PERSONAJE.}

El nombre completo del personaje Sidi Bulgayz -los moriscos, en español, escribían su nombre "Siti Bulgaiz”-, es, en árabe, Sidi Muhámmad Abu-l-Gayz Al-Qashshash4. Es una

* $\quad$ Este estudio se ha realizado en el marco del proyecto de investigación Edición digital de los textos en español de los mudéjares y moriscos y su contexto historiográfico, con la referencia BFF2002-02497, del Plan Nacional de Investigación Científica, Desarrollo e Innovación Tecnológica, cofinanciado con FEDER y concedido en el año 2002.

1. Agradezco al Dr. Abdel-Hakim Gafsi Slama, historiador e hispanista especialista en mo riscos e inspector general de arqueología en el Instituto Nacional del Patrimonio, del Ministerio de Cultura, de Túnez, el haberme proporcionado un ejemplar de la edición de donde he extraído los dos textos en árabe, edición tanto tiempo esperada del manuscrito del siglo XVII, así como también algunas provechosas informaciones para este trabajo.

2. L. P. Harvey, "Textes de littérature religieuse des moriscos tunisiens», en M. de EpalzA - Ramón PetiT, Receuil d'études sur les moriscos espagnols en Tunisie, Madrid, 1973, 199-204 [traducido de cuatro pasajes de su tesis inédita en inglés The literary culture of the moriscos (1492-1609), Oxford, 1958].

3. Ver las principales manifestaciones de esta colaboración, en este mismo volumen de Homenaje al Prof. Leonard Patrick Harvey, Sharq Al-Ándal u s. Estudios Mudéjares y Moriscos, en M. de EpAlZA, «Testimonio de décadas de colaboración con el Prof. Harvey», ibid., pp. 5-13.

4. Transliteración del árabe: Muhammad Abū-l-Gayt al-Qaššāš. Ver un pequeño estudio semántico de las diversas partes de su nombre árabe al final de este trabajo: Apéndice filológico: ANÁLISIS SEMÁNTICO DEL NOMBRE DE SIDI BULGAYZ. 
importante personalidad tunecina de principios del siglo XVII, principal valedor de los moriscos expulsados de España y refugiados en Tunicia 5 .

Era un personaje religioso, de gran influencia social en la sociedad tunecina cuando se refugiaron en Túnez los moriscos expulsados de España, a p rincipios del siglo XVII. Puso su influencia en favor de la acogida e inserción de los inmigrantes, de acuerdo con el soberano local Uzmán Dey, rep resentante del califa y sultán otomano de Estambul Ahmad I (soberano entre 1603 y 1617) ${ }^{6}$. Esta acción figura en todas las fuentes contemp oráneas que tratan de la instalación de los moriscos, tanto en árabe como en español, y en los numerosos estudios modernos. La publicación reciente de una ya conocida fuente manuscrita ${ }^{7}$ ofrece la ocasión de analizar un poco más detenidamente este tema de la acogida en Túnez de los moriscos, con el papel del personaje Sidi Bulgayz, el papel de las autoridades otomanas y el de la sociedad tunecina en ese país árabe, islámico y turco-otomano ${ }^{8}$.

5. Ver J. Oliver Asín, «Un morisco tunecino admirador de Lope. Estudio del Ms. S.2 de la Colección Gayangos», Al-Andalus, Madrid, 1/2, 1933, 409-450 (especialmente p. 412). Presentado y traducido al francés en M. de Epalza - R. PetrT, o. c., 205-239. Las páginas del morisco tunecino que se refieren a Sidi Bulgaiz y a la instalación de los moriscos han sido estudiadas también y traducidas al francés por Henri PIÉRI, «L' acceuil par des Tunisiens aux morisques expulsés d’Espagne: un témoignage morisque», IBLA, Túnez, 121, 1968, 63-72, artículo presentado y reeditado en M. de EpALZA - R. PETIT, o. c., 128-134. Sobre el fondo de libros de Gayangos, notable historiador y arabista del siglo XIX, ver reciente presentación de Fernando DíAz ESTEBAN, «Informe acerca del contenido e importancia de la Colección Gayangos en la Real Academia de la Historia», Boletín de la Real Academia de la Historia, Madrid, CXCIX/I, 2002, 61-88.

6. Ver Robert Mantran, «Ahmad 1 er», Encyclopédie de l’Islam, Leyden - Paris, eds. E. A. J. Brill - G.-O. Maisonneuve et Larose, 1960 (2. ${ }^{a}$ ed.), 1991 (3. impres.), II, 275-276, también versión inglesa; versión turca, por Cavid BAYsun, « ‘ Ahmed I», Islam Ansiklopédesi, Estambul, 1940, I, 181-184.

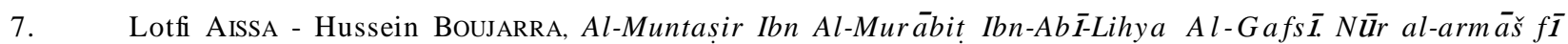

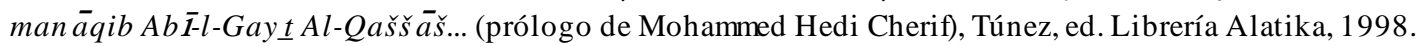

8. Ver principales obras de conjunto sobre el tema de los moriscos después de la expulsión: M. de EPALZA Ramón PetiT (edits.), o. c. [32 trabajos, en francés]; Slimane - Mostafa ZBISs - Abdel-Hakim GAFSI Mohiedine Boughanmi - M. de Epalza (edits.), Études sur les morisques andalous, Túnez, ed. Institut National d'Archéologie et d’ Art, 1983 [18 trabajos, en árabe, en español y en francés]; M. de EpAlZA (edit.), L'expulsió dels moriscos. Conseqüències en el món islàmic i en el món cristià. Congrés Internacional. 380è aniversari de l'expulsió dels moriscos. Sant Carles de la Ràpita 5-9 de desembre de 1990, Barcelona, ed. Generalitat Catalana. Conselleria de Cultura (col. Actes de Congressos, 5) [43 trabajos, en catalán, en español, en francés, en inglés].

Tratamiento general del tema en M. de EpAlzA, Los moriscos, antes y después de la expulsión, Madrid, ed. Fundación MAPFRE, 1992, 1994, 1997; Alicante, 2002, en Biblioteca Virtual «Miguel de Cervantes Saavedra», en María Jesús RuBIERA MATA (dir.), portal «Literatura de Mudéjares y Moriscos», Alicante, 2001, (http: //cervantesvirtual. com/portal/lmm), y Muhammad RAzūQ (Mohamed RAzouK), Al-Andalusiyyūn wa-hi $\hat{y} r a \bar{t} u$-hum ilà Al-Magrib jil āl al-qarnayn 16-17 (Los moriscos y sus emigraciones a Marruecos durante los siglos XVI y XVII), Casablanca, ed. Ifrīqiya Aš-Šarq, 1989. También monog rafías 
El personaje Sidi Bulgayz y la problemática general del papel de los santones o morabitos en la sociedad tunecina de principios del XVII ha sido bien estudiada por el profesor Taoufik Bachrouch, que le dedica un capítulo especial en el que resume la biografía del personaje ${ }^{\text {. Sobre }}$ su biografía, hecha por su discípulo Ibn-Abī-Lihia Al-Gafsīe se puede ver la presentación general, bien situada en la historiografía tunecina de la época, en la tesis doctoral del profesor de la Universidad de Túnez Ahmad Abdesselem ${ }^{10}$ y el prólogo, del también profesor de Túnez Muhammed Hedi Cherif, a la edición de Aissa y Boujarra ${ }^{11}$. Una presentación crítica de esta edición hace notar la importancia de este texto, escrito unos meses después del fallecimiento de Sidi Bulgay z (1621) por su sucesor a la cabeza de su cofradía, para el conocimiento de muchos movimientos sociales tunecinos a fines del siglo XVI y principios del XVII ${ }^{12}$.

Sidi Bulgayz y su importancia en la acogida e instalación de los moriscos expulsados de España en territorio tunecino son ya conocidos, especialmente por los estudios de Jaime Oliver Asín ${ }^{13}$ y de Jean Pignon ${ }^{14}$. También se ha estudiado desde hace tiemp o su envío a Estambul -al sultán Ahmad 1. ${ }^{\circ}$, recién ascendido al trono otomano-, en 1603, de un ejemplar de una muy conocida

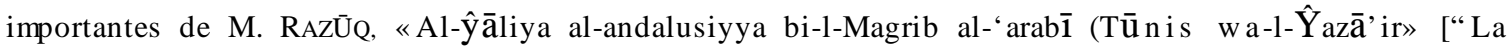
comunidad andalusí en el Magreb árabe (Túnez y Argelia)”], Al-ma ŷalla at-tār ījiyya al-magribiyya (al-‘ahd al-ḥadīt wa-l-mu'āṣir). Revue d’Histoire Maghrébine (Époque moderne et contemporaine), Zaghouan, 13/43-44, 1986, 109-144; Ahmad BADR, «Al-andalusiyyūn wa-l-magāriba fī-l-Quds» [“ Los andalusíes y los magrebíes en Jerusalén”], Awr āq, Madrid, VI, 1983, 125-139.

9. «Sidi Bilghith al-Qashash: un saint charitable», en T. BACHROUCH, Le Saint et le Prince en Tunisie. Les élites tunisiennes du pouvoir et de la dévotion. Contribution à l'étude des groupes sociaux dominants (1782-1881), Túnez, ed. Université de Tunis, 1989, pp. 107-126, que lo estudia como uno de los antecedentes de los dirigentes político-religiosos del siglo XIX, objeto central de su libro. Es un fenómeno que se daba también en otras regiones del Magreb, especialmente en la sociedad marroquí, cuyos soberanos a partir del siglo XV subieron al poder generalmente por su fuerza religiosa y política, basada en la nobleza que tenía su origen en ser descendientes del profeta Mahoma/Muhámmad, porque eran “cherifes” o “chorfas” (d el árabe šarīf, plural šurafā', “ noble, nobles”).

10. Ver A. Abdesselem, Les historiens tunisiens des XVIIe, XVIIIe et XIXe siècles: essai d'histoire culturelle, Paris, 1973, 149-153.

11. Ver L. Aissa - H. BoujARra, o. c., pp. 1-2 [en árabe] y 582-585 [en francés].

12. Ver Sami BARgAOUI, « L’hagiographie et l’historien: les pièges de l'écriture. A propos de la publication de l’ ouvrage d'Al-Muntasir B. al-Murâbit...», correspondances. Institut de Recherche sur le Magreb Contemporain, Túnez, 2001, 11 pp. (wysiwyg: //8/http: /www. Irmcmaghreb.org/corres/textes/bargaoui.htm)

13. J. OLIVER Asín, o. $c$.

14. J. PIgnON, «Un document inédit sur la Tunisie au début du XVIIe siècle», Les Cahiers de Tunisie, Tún ez, 33, 1961, 108-219, y «Une géographie de l’Espagne morisque», id., 14, 1966, 286-300 [presentado y reproducido en M. de Epalza - R. PetiT, o. c., 64-76]. 
obra de polémica anticristiana en árabe, pero con traducción al turco: la Tuhfa del escritor bilingüe en árabe y en catalán Abdal-lāh At-Tarchumán, el funcionario de aduanas de Túnez nacido en Mallorca con el nombre cristiano de Anselm o En Telm Turmeda y antiguo fraile franciscano convertido al islam ${ }^{15}$. Este dato es una manifestación de sus sentimientos religiosos profundamente anticristianos y de sus buenas relaciones políticas con la corte de Estambul.

Los textos que aquí se presentan han sido ya editados, en italiano y en árabe ${ }^{16}$. Pero esta presentación y traducción en español son "nuevas" en el sentido de que se estudian en un contexto más amplio del considerado hasta ahora, en la política general de acogida y de instalación de los moriscos en el conjunto del Imp erio Otomano y, particularmente, en la provincia ("vilayet" o "regencia") de Túnez ${ }^{17}$. También son "nuevos" en el sentido de que estaban editadas en publicaciones tunecinas poco accesibles y en lenguas tamp oco muy fáciles de entender para la may oría de los historiadores (italiano del XVII, por un capitán inglés; árabe lleno de localismos y de referencias religiosas de cofradías musulmanas de las sociedades magrebíes de la época, que hay que explicar; italiano del sur, lleno de dialectalismos).

Estos textos, que presentan la instalación de los moriscos desde el interior mismo de la sociedad tunecina, ap ortan una visión parcial pero muy directa de ese fenómeno social, tanto en sus orígenes políticos como en las tensiones que producen. Hay algunos elementos novedosos, junto a los ya conocidos o que eran sólo hipótesis, ahora más o mejor confirmadas.

\section{PRIMER TEXTO EN ITALIANO (CAPITÁN ELLYATT, 1613)}

El primer texto relacionado con Sidi Bulgayz, aunque no directamente con los andalusíes o moriscos, es el de un capitán inglés, esclavo de la sup rema autoridad tunecina, Uzmán Dey, quien

15. Ver M. de EpAlzA, Fray Anselm Turmeda ('Abdallāh al-Tar ŷumān y su polémica islamo-cristiana. Edición, traducción y estudio de la TUHFA, Roma, ed. Accademia Nazionale dei Lincei, 1971; reimpresión con nueva introducción y nuevo prólogo, con el título Fray Anselm Turmeda ('Abdallāh al-Tar ŷumān) y su polémica islamo-cristiana. Edición, traducción y estudio de la TUHFA, Madrid, ed. Hiperion, 1994, 48-50, 177.

16. Ver referencias a continuación.

17. Sobre esa política, ver Abdeljelil Temimi, Le Gouvernement Ottoman et le Problème morisque, Zaghouan (Tunicia), ed. CEROMDI, 1989, especialmente «Lettre du sultan Ahmed premier au Doge de Venise en 1614», o. c., pp. 32-37 (en francés) y 39-48 (en árabe); ID., Études d’Histoire Mor is que, Zaghouan, ed. CEROMDI, 1993; ID., «Évolution de l'attitude des autorités de la Régence de Tunis face à l'acceuil des Morisques, à la lumière d'un nouveau firman du sultan ottoman», Revue d'Histoire Maghrébine, Zaghouan, 20/69-70, 1993, 169-180 (en francés), 56-70 (en árabe); M. de EpalzA, «Les Ottomans et l’insertion au Maghreb des Andalous expulsés d’Espagne au XVIIe siècle», Revue d’Histoire Maghrébine, Túnez, 31-32, 1983, 165-173; ID., «Estructuras de acogida de los moriscos emigrantes de España en el Magreb (siglos XIII al XVIII)», Alternativas. Cuadernos de trabajo social, Alicante, 4, 1996, pp. 35-58; ID., "Instalación de moriscos en Anatolia (documento Temimi, de 1613)», Sharq Al-Andalus. Estudios Mudéjares y Moriscos, Teruel - Alicante, 13, 1996, pp. 145-157. 
compartió con el santo personaje la política de protección de los inmigrantes moriscos cuando llegaron en masa a Tunicia, hacia 1610. El Capitan Elly att escribió un informe sobre su estancia en la regencia de Túnez entre 1609 y 1613 y sobre este país. El texto, en italiano, ha sido editado y estudiado por el historiador francés Jean Pignon, ampliando lo referente a ambos personajes tunecinos y a su relación con los moriscos, especialmente con la traducción de algunos fragmentos del manuscrito árabe de Ibn-Abī-Lihy a Al-Gafsī, entonces inédito, que se estudiará a continuación, en este trabajo ${ }^{18}$. Jean Pignon también se ha ocupado de los moriscos expulsados en una larga reseña ${ }^{19}$ en la que completa con informaciones tunecinas la obra del también historiador francés Henri Lap eyre ${ }^{20}$.

La importancia del texto se basa sobre todo en su información sobre el origen del poder político de ambos personajes, el político y militar Uzmán Dey y el religioso administrador de cuantiosos bienes "habices" ${ }^{21}$ Sidi Bulgayz, y asimismo en el origen de sus mutuas relaciones o alianzas. El testigo inglés refleja lo que se decía del origen de ese poder y de esa alianza en el ambiente de la "corte" tunecina del Dey, mientras que el sucesor y biógrafo de Sidi Bulgayz al frente de la cofradía refleja la versión hagiográfica del personaje, en relación con el poder político de los dos primeros soberanos tunecinos, Uzmán Dey y Yúsuf Dey. Los historiadores posteriores, tanto los árabes del siglo XVII como el mismo Jean Pignon, en el XX, intentarán hacer una síntesis, que este último expondrá con los documentos históricos árabes. Estos textos y estudios se comentarán a continuación de la traducción del texto italiano al español.

«Caraosmán"2, que últimamente era Dey de Túnez, del cual yo era esclavo, vino de

18. J. PIGNON, «Un document inédit...

19. J. Pignon, «Une géographie de l’Espagne morisque», Les Cahiers de Tunisie, Túnez, XVI, 1966, 286-300, reproducido en M. de EPALZA - R. PETIT, o. c., 64-76.

20. H. LAPEYRE, Géographie de l'Espagne morisque, París, ed. S.E.V.P.E.N. (col. Démographie et société, II), 1959 [traducido al español, Geografía de la España morisca, Valencia, ed. Diputació Provincial de València (col. Història i societat, 4), 1986, pero sin los índices onomásticos].

21. Ver una visión general de esta institución musulmana, de bienes raíces por motivos y con carácter religiosos islámicos, en W. Hefferning, "Waqf or Habs», en H. A. R. GiBb - J. H. Kramers (edits.), Shorter Encyclopaedia of Islam, Leiden - London, 1961, 624-628. Se puede ver una ampliación y renovación de este artículo en el volumen XI/178-180, de la Enciclopedia del Islam (en francés y en inglés), Leiden, 2003, entrada «WAQF», especialment e los artículos de R. PETERS, «Según el derecho musulmán clásico», D. S. POWERS, «En el Norte de África hasta 1914» y Alfonso CARMONA, «En España musulmana» (en edición en francés pp. 65-70, 76-82 y 82-86, respectivamente).

22. En turco, “el negro Uzmán”, denominación o mote del que es más conocido con el título político-militar de “Uzmán Dey”, que obtendrá más tarde, en 1591, a partir de su toma del poder en Túnez como jefe del DĪwān o Consejo militar del territorio tunecino, dentro del Imperio Turco-Otomano, como se explicará a continuación, en este documento. 
Constantinopla ${ }^{23}$ a Berbería ${ }^{24}$ para servir voluntariamente en la galera en la que llegó. Se puso a hacer de Macellaro ${ }^{25}$ durante dos años. Era sagaz y de ingenio sutil. Se fue arrimando a un gran Marabuto ${ }^{26}$, al que los de Túnez tenían en alta veneración. Se hizo apreciar tanto que obtuvo un cargo entre los genízaros ${ }^{27}$. Por las esperanzas y buenas perspectivas sobre su persona que daba a toda la milicia comenzó a hacerse apreciar. Tanto logró que obtuvo como esposa a la hija de uno de los principales y más ricos Moros de Túnez ${ }^{28}$, llamado Sidi Cubir ${ }^{29}$, del cual obtuvo todos los tesoros que quiso. De esta manera y con el apoyo y favor del dicho Marabuto se hizo tan fuerte en sus apoyos y proyectos entre los genízaros que se convirtió en Capitán General de ellos y de toda la milicia de aquel Reino. Fue el primero que tomó el título de Dey. Con esta dignidad ha dominado durante 15 años, absolutamente sin ninguna oposición ni dificultad. Igualmente fue el primero en introducir el corso contra cristianos, en naves "tondi et bertoni" [...]» ${ }^{30}$.

El texto italiano nos informa que Cara Uzmán vino en barco de Estambul y que se ocupó en diversos trabajos civiles en Túnez, con relaciones cada vez más fuertes con Sidi Bulgayz, al que servía y que le apoyaba, y que le recomendó ante el estamento militar turco y ante el de la rica burguesía árabe de Túnez. La biografía hagiográfica de Ibn-Abī-Lihya Al-Gafsīin en árabe, nos afirmará que estuvo sencillamente al servicio de la cofradía de Sidi Bulgayz, precisando con un

23. Constantinopla, la vieja denominación griega del Istanbul turco e Istānā en árabe (Estambul en castellano), desde su conquista en 1453, cuando se transformó en capital del Imperio Turco-Otomano.

24. Denominación geográfica que abarca el Magreb en general, pero que en el siglo XVII se reservaba a la parte del Norte de África que comprende los actuales estados de Argelia, Túnez y Libia, provincias, vilayet o “regencias” del Imperio Otomano.

25. J. PignON, « Un document inédit..., p. 61, traduce el término como “ carnicero... zapatero”, pero añade que el biógrafo de Sidi Bulgaiz y su sucesor al frente de la cofradía, Ibn-Abī-Lahya Al-Gafsī, cuyo texto se estudia más adelante en este trabajo, dice en árabe que "Ce turc était employé avec les pauvres (=les affiliés) à la zaouia [du cheikh]. Il portait sur la tête le pain en pâte jusqu'au four et le rapportait une fois cuit. [Este turco trabajaba al servicio de los miembros de la cofradía, en el convento o záguiya del jeque [Bulgaiz]]».

26. “Personaje religioso, de gran santidad”, generalmente fundador o director de una cofradía religiosa, de gran poder espiritual y económico, ya que administraba los bienes que los fieles y devotos musulmanes consagraban a la religión, detrayéndolos así de la codicia del Estado y sus representantes político militares, al menos en alguna manera. Este “marabuto” es Sidi Bulgaiz. Ver más adelante y el estudio socio-político y religioso de T. BACHROUCH, o. c.

27. Militares de la administración imperial turco-otomana.

28. «Moros» designa a los árabes tunecinos, en contraposición con los turcos o asimilados, o de otro origen foráneo.

29. J. Pignon, o. c. (n. 79) identifica el nombre de este personaje religioso como “El Gran Señor o Monseñor, el Gran Reverendo" (as-sīd $\overline{1} a l-k a b \bar{r}$ ).

30. J. PignON, « Un document inédit..., texto italiano, p. 128, y notas explicativas en francés, pp. 185-186. 
detalle ese servicio:

«Ese turco estaba empleado con los pobres (=los afiliados) en la záwiya ${ }^{31}$. Llevaba sobre su cabeza, hasta el horno, la pasta del pan, y lo volvía a traer una vez cocido» ${ }^{32}$.

Ambos textos se confirman mutuamente en lo principal, la íntima relación política entre ellos al principio de la carrera política del turco. Pero el capitán Ellyatt insiste más en los oficios personales del futuro dey y en su ascensión entre los militares genízaros del Dīwān o gobierno supremo de la regencia, mientras que el biógrafo religioso Ibn-Abī-Lihya Al-Gafsī precisa el humilde trabajo del futuro soberano, al servicio del director de la cofradía. El Capitán Ellyatt identifica al personaje de Sidi Bulgayz más adelante ( $\mathrm{f}^{\circ}$ 24): «il gran Marabout chiamato Sidi-Balahid ${ }^{33}$.

Pignon cree también que Sidi Bulgay z estuvo implicado en los acontecimientos de 1590-91 que concluy eron con la matanza de los jefes del Diwán y el encumbramiento de Uzmán Dey con los suy os al poder supremo de toda la vilayet o regencia otomana de Túnez ${ }^{34}$. El historiador tunecino de finales del siglo XVII Ibn-Abī-Dinār cuenta lo que es quizás una ley enda, pero que de todas formas es muy significativa:

«Los jenízaros vinieron a implorar su apoyo y hasta a querer obligarle a que les apoyara. Él envió a algunos de los miembros de su cofradía ${ }^{35}$ al matadero y les encargó que le trajeran cabezas de cordero. Le trajeron muchísimas. La matanza del Dīwān serealizó inmediatamente después y se atribuyó a este aviso mudo del jeque» ${ }^{36}$.

No parece que las relaciones entre ambos personajes hubieran sido siempre excelentes,también según Pignon ${ }^{37}$,como se ve en las diversas versiones que corrieron sobre la causa de la muerte de Uzmán Dey: “[Ellyatt] alude también a un enfrentamiento que habría nacido

31. Zāwiya, el convento o la cofradía del jeque.

32. La traducción francesa del texto árabe, con las necesarias explicaciones, son de J. PiGNON, o. c., p. 185.

33. J. Pignon añade : «Le cheikh Sodo Ab̄̄l Cait el Qachchāch (dont le nom, transcrit de façons différentes, apparaît dans les textes sous la forme «Sidi Belghits» ou «Sidi Belcris» ou «Sidi El Kechach» ou «El Kessas»), est un personnage célèbre», ibid..

34. Ver J. Pignon, l. c. Es ya un hecho reconocido por todos los historiadores de la historia de la época, especialmente en la excelente síntesis, en profundidad, de T. BACRouch, Formation Sociale Barbaresque et Pouvoir à Tunis au XVIIe Siècle, Tunis, ed. Université de Tunis, 1977, p. 134.

35. Literalmente: los “pobres”, los fuqar $\bar{a}$, , faquires.

36. J. PigNON, l.c.

37. Ibid. 
entre los dos hombres, en 1609, a propósito de los demasiado numerosos cristianos que había en la armada tunecina ${ }^{38}$. Por otra parte, el biógrafo del jeque escribe que el dey habría maltratado, en cierto momento, a los fieles de Sidi Bulgay z. Éste último habría profetizado «tendrá una desgracia», y efectivamente Uzmán murió al poco tiempo, por una enfermedad, según Ibn-Abī-Dinār, y de una caída de caballo, según Elly att, el cual parece ver en este acontecimiento (ocurrido tres días después de una dura paliza a la que le condenó el Dey) una manifestación de la justicia divina”.

De todas maneras, el texto italiano contemporáneo, cotejado con fuentes árabes del siglo XVII, contemp oráneas o p osteriores, estudiadas p or Jean Pignon, abren -a p esar de ser relativamente pobres en información- algunas perspectivas imp ortantes sobre el contexto político tunecino y sobre algunos de sus antecedentes, en el momento de la llegada de los moriscos, a principios del siglo XVII. El papel de Sidi Bulgayz en este contexto quedará aún más claro con el análisis de los otros dos textos de su biógrafo, que se van a presentar a continuación.

\section{PRIMER TEXTO EN ÁRABE (HAGIÓGRAFO IBN-ABĪ-LIHYA, 1623)}

Para situar aún mejor la importancia del personaje Sidi Bulgayz Al-Qaššāš en la acogida de los andalusíes o moriscos expulsados de España en los primeros años de su instalación en la Regencia de Túnez, traducimos y comentamos a continuación el y a mencionado texto en árabe de su biografía hagiográfica, realizada por su discípulo y sucesor al frente de su cofradía Al-Muntașir Ibn-al-Murābit Ibn-Abī-Lihya ${ }^{39}$. Su valor princip al reside en que esa biografía, evidentemente hagiográfica pero redactada por alguien que conocía muy bien su actividad social, se acabó de escribir sólo 11 meses después de la muerte, por peste, del jeque de la cofradía, que tenía 73 años, en el año 1031 de la Hégira (entre el 16 de noviembre de 1621 y el 4 de noviembre de 1622) ${ }^{40}$.

El capítulo segundo de ese libro está consagrado a "Lo que hizo con los andalusíes y lo que a ellos se refiere..." ${ }^{\text {41 }}$. Este largo texto -que traducimos por primera vez del árabe, a continuación-refleja las tensiones sociales que provocó en Túnez la llegada masiva de los moriscos o andalusíes expulsados de España y cómo los jefes andalusíes pactaron su instalación en el país, bajo la dirección del andalusí Ibn-'Abdi-r-Rafī', con las diversas autoridades locales, turcas y árabes, gracias a la mediación y al apoyo de Sidi

38. Los sentimientos anticristianos de Sidi Bulgayz, seguramente acrecentados por los sufrimientos de los moriscos expulsados de España, se manifiestan en el hecho de que ya en 1603 hizo traducir al turco y enviar al sultán de Estambul Ahmad $1^{\circ}$ el texto bilingüe de la Tuhfa de Turmeda/At-Tarŷumān, virulenta aunque muy tradicional polémica contra las creencias cristianas. Ver estudio de este hecho en la mención anterior de M. de EpALZA, Fray Anselm Turmeda...

39. Ver ese testimonio excepcional de su tiempo y de su sociedad, en la edición y estudios de L. AissA - H. BOUJARRA, o. C.

40. Dato extraído del historiador tunecino de fines del XVII Ibn-Abī-Dinār, en J. PIGNON, o. c., p. 186 , don de informa también que la dicha peste fue muy mortífera en el país y fue llamada “ peste de Sidi Bulgayz”.

41. O. ., pp. 138-141. 
Bulgay $z^{42}$.

El segundo texto informa, en forma de sueño, sobre la imp ortancia de Sidi Bulgay z para unos granadinos o castellanos de fines del XVI, que tenían apellidos españoles y estaban de paso por Gafsa, al sur de Túnez ${ }^{43}$.

\section{CAPÍTULO 2}

Su actividad con los andalusíes y lo que hizo en su favor el difunto -¡Dios esté satisfecho de él!-$\operatorname{Dios}^{44}$ :

Cuenta el autor de este texto, el siervo de Dios y pobre devoto, que cuenta con la ayuda de

Cuando vinieron los andalusíes a Tunicia yo estaba en Túnez realizando una peregrinación religiosa ${ }^{45}$. Cierto día, estando yo fuera de la puerta oriental de la Mezquita Mayor del Olivo ${ }^{46}$, me encontré con los jefes principales de los andalusíes ${ }^{47}$. Tenían en sus manos una hoja de papel y buscaban quien se lo leyera. Por casualidad se dirigieron a mí y me dijeron ${ }^{48}$ :

- ¿Puedes leer la escritura del Jeque Sīdī Abū-l-Gayt ${ }^{39}$

Contesté que sí.

42. Ver la entrada «Abī al Gayṭ al-Qaššāšs, según otras fuentes, es pecialmente las de los propios moriscos, en español, en el índice onomástico de M. de EpAlzA - R. PETrT, o. c., p. 396, y fotografías de su mausoleo, conservado en la Medina de Túnez, ilustraciones 11 y 14 (ibid., pp. 120 y 130).

43. Se estudiará en el apartado 3 de este trabajo: SEgundo teXto en ÁRABE (HAGiógrafo IBN-ABĪ-LiHYA, 1622).

44. El autor del libro se refiere a sí mismo, Al-Muntașir Ibn-al-Murābit Ibn-Ab̄̄-Lihya, como autor de este texto

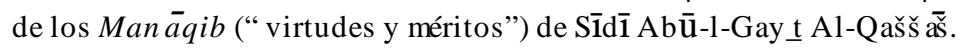

45. Una ziyāra o “visita” a lugares religiosos, especialmente mausoleos de fundadores de cofradías piadosas.

46. $\quad \hat{Y} \bar{a} m i$ ‘ $a$ az-zit ūna, en el centro de la vieja Medina de Túnez.

47. Kubarā'al-Andalus wa-mašă'ija-hum.

48. En realidad no es que no supieran el árabe o el contenido del escrito que traían, porque entre ellos estaba Ibn-'Abdi-r-Rafi', notable escritor en árabe, sino que querían que se les atestiguara la autenticidad del documento de Sidi Bulgayz y acudían para ello ante su discípulo y sucesor al frente de su cofradía, en una acción política que no era en manera alguna "por casualidad”, como afirma modestamente Ibn-Abī-Lihya, para reforzar la acción de los andalusíes, con los que estaba seguramente aliado, y al mismo tiempo para tomar distancia política de ellos, como se verá a continuación.

49. Šayj, “anciano”, título de respeto, tanto político o tribal (“jefe, jeque”) como religioso (“director de cofradía”). 
Me enseñaron entonces una hoja escrita con tinta verde ${ }^{50}$, en la que estaba escrito: «iAlabado sea Dios! $!^{51}$

¡Dios bendiga y salve al Mensajero de Dios! $!^{52}$

A nuestros señores, los jefes de los andalusíes ${ }^{53}$, especialmente al señor fulano y al señor zutano [nombró así hasta diez nombres de los principales personajes andalusíes ${ }^{54}$ ]. Después de los saludos habituales, implorando para vosotros la paz y las bendiciones de Dios, no se puede más que alabar a Dios -iensalzado sea!- por todos los bienes con los que quiere alegraros. Yyo estoy a vuestra disposición para anunciaros estos bienes. Nos habéis llamado para que yo pida a Dios estos bienes para vosotros. Primero lo he pedido por mediación de mi padre. Segundo, de noche, por mediación de mi maestro Sīdī Muhammad Hadîfa, compañero del Mensajero de Dios. Tercero, también de noche, por mediación de mi padre. Y he visto que obtendríais bienes, a pesar de las divergencias en el asunto de Mahdia ${ }^{55}$. Vosotros sois, como dijo el poeta -en metro basitt-:

50. Los principales colores de los manuscritos de la época son el negro (a veces herru mbrado en marrón), el rojo y el verde, este últimos empleado como adorno o para subrayar algunas palabras. El verde, color del islam, podría querer poner de relieve el carácter sagrado o religioso del documento.

51. Fórmula habitual de profesión de fe, para iniciar un texto y para dar gracias a Al-lāh, el Dios único del monoteísmo islámico.

52. Muhámmad, Mahoma, el profeta del islam. Es la segunda parte de la profesión de fe esencial de esta religión.

53. Ilà s ādati-nā al-andalusiyya, al pie de la letra “ nuestros señores del colectivo de los andalusíes”.

54. Min akābiri-him, “ de sus magnates, de los principales de ellos”.

55. En nota de los editores se emite la hipótesis de que Sidi Bulgaiz se refiriera al deseo de algunos moriscos de instalarse en la región de Mahdia, en la costa oriental tunecina, lejos de la zona asignada por las autoridades turcas, que era exclusivamente el "alfaz” de los alrededores de la capital tunecina [fahs, campo agropecuario cerca de una población y dependiente de ella, a no confundir con hạaz, “alfoz”, s egún estudio de M. de EPAlZA, «La dualidad Campello-Fahș en el espacio agrícola de Al-Ándalus (Alicante - Castalla - Pedreguer - Madrid)», Sharq Al-Ándalus. Estudios Árabes, Alicante, 4, 1987, 159-173]. Esta divergencia de los moriscos con Uzmán Dey es mencionado por otras fuentes coetáneas, en textos en español y en árabe. La información expresa de este texto es sólo del hecho del enfrentamiento, de que Uzmán Dey pareció ceder y de que el proyecto andalusí fracasó. Pero el que muchas fuentes lo mencionen me hacen pensar que fue un problema muy importante, un “problema de Estado”, en la instalación de los moriscos en Tunicia. Se trataba de que algunos andalusíes querían tener un puerto importante, la his tó rica Mahdia/África, capital de la dinastía Fatimí en el s. X y ocupada por España entre 1550 y 1554, de situación privilegiada, a unos 200 kms. al S. de Túnez, prácticamente incontrolable desde la capital Túnez, desde su puerto de La Goleta y desde su bahía, ni de la de Bizerta, al N. del país. La aspiración andalusí de poseer su propio puerto comercial y militar, como Cherchel/Argel y Salé/Rabat, chocaba con los intereses de las autoridades turcas (y magrebíes, en general). Pienso desarrollar más este tema en un próximo trabajo "Ambiciones políticas de los moriscos en su exilio (Marruecos, Argelia, Túnez) y la “crisis de Mahdia” (1610)» y agradezco al Dr. Luis F. Bernabé Pons, catedrático de Estudios Árabes e Islámicos de la Universidad de Alicante y experto en historia y literatura de los moriscos, el que me haya planteado el interrogante de esta “crisis de Mahdia”, tan repetidamente 
«Todo territorio en el que os instaléis se felicitará, porque sois como la lluvia que ensombrece la tierra.

La gente que os vea os esperará con mirada favorable, porque ellos os verán como cimas de la humanidad. Si vino una caravana para liberar la tierra vuestra, es como un perfume que atrae el caminar del pueblo.

Dios no prive a mi mirada de ver vuestra belleza, vosotros que mencionáis siempre a Dios, en el fondo de vuestras entrañas y de vuestro corazón ${ }^{56}$.

Saludos a todos vosotros, con la paz de Dios, con su misericordia ysus bendiciones, de parte del autor de este texto, el siervo de Dios y pobre devoto Abü-l-Gayț.».

Entonces ellos cogieron la hoja de mi mano y se fueron muy contentos, porque pensaban que las palabras del difunto Jeque -iDios esté satisfecho de él! ${ }^{57}$ - era un buen presagio para el futuro de sus asuntos.

Cuando vinieron los andalusíes a Túnez, les faltaron aprovisionamientos, formas de vida colectiva, mercados para vender y comprar, mezquitas, casas donde vivir, almacenes y tiendas. Se dirigieron entonces al Jeque para que les obtuviera algo. Éste - ¡Dios esté satisfecho de él!- se apresuró como el viento a enviarles comida para alimentarse y vestidos para cubrirse. De esta forma yo lleguéa contar que salieron, para alimentarles, 1.200 panes de trigo y dos cafices de trigo fino y triturado para el alcuzcuz, en parte seco y en parte ya elaborado con su salsa, ambos con sus correspondientes cantidades troceadas de cordero. Además, leche y carne, y dos cabezas de bovino, cada día. Todo eso durante todo el año, como forma de hospitalidad del Jeque -iDios esté satisfecho de él!-.

Él -iDios esté satisfecho de él!- tenía tres tandas de comidas en su casa: la tanda que salía por la tarde, hasta antes de la puesta del sol, para los que estaban en las escuelas y en las cárceles; otra tanda, desde la puesta del sol hasta la noche oscura, para los huéspedes, los devotos pobres y los menesterosos; y una tercera tanda, al llegar a la noche oscura y más tarde, a disposición de los huéspedes que venían de noche a alojarse, para la gente pobre y devota y para los menesterosos que estaban alojados en la entrada de la

mencionada por las fuentes contemporáneas.

56. Para el origen histórico y los niveles de interpretación --peregrinación, mística, exilio...- de estos versos, ver más adelante.

57. Fórmula musulmana para referirse a un difunto, equivalente al “descanse en paz” en castellano. 
casa $^{58}$ o en los edificios de la cofradía ${ }^{59}$. Este sistema de tandas para los alimentos, lo tenía el difunto Jeque -¡Dios esté satisfecho de él!- siempre y ordenadamente, sin interrupción y sin límite. Para la tanda diurna, antes del mediodía, disponía de 800 o 1.000 panes que enviaba cada día a los que estaban permanentemente en las cárceles, y lo enviaba también a los estudiantes de las escuelas. Lo restante era para los huéspedes que se albergaban en las residencias de la cofradía y para los pobres devotos que estaban en la entrada de la casa. Esto lo hacía por obtener la bendición de Dios.

El difunto -¡Dios esté satisfecho de él!- ayudaba y hacía el bien a quien obraba bien con él, como eran el pachá, los beys y los deys ${ }^{60}$, entre otras principales autoridad y personajes superiores de Túnez. Decía:

« ¡ Si no me portara bien con ellos, no habría siervo de Dios pobre y devoto que me reconociera como Abü-l-Gayt Al-Qaššăš!»».

Esta era su actitud -¡Dios esté satisfecho de él!-.

Cuando se multiplicaron los andalusíes en Túnez y se fueron instalando en sus territorios y poblaciones, poblaron en especial la $\hat{Y}$ azīra ${ }^{61}$. Se multiplicó el número de pueblos en los que se instalaron, mejoró su situación con la mejora de sus campos de cultivo y formaron familias. Fueron polo de atracción para gente que venía de todas partes a sus pueblos, para visitar y venerar al Jeque Sīdī Abü-l-Gayt - i Dios esté satisfecho de él!-. De su mano recibían un contrato, uno para cada grupo ${ }^{62}$ de cada pueblo. Para cada grupo él nombraba un delegado ${ }^{63}$. Este delegado era el jefe o jeque de los pobres devotos ${ }^{64}$.

58. En la darỉ̉a, sala interior o zaguán de recepción, con un banco corrido, donde el señor de la casa recibe a los visitantes que no quiere hacer pasar al patio interior o residencia de la familia y a su salón, más solemnemente adornado, donde recibe y come con sus visitantes más apreciados e íntimos y con sus parientes.

59. Zāwiya, etimológicamente, el “rincón”, convento, mezquita menor con escuela diurna y albergue nocturno, a veces alrededor de la tumba de un personaje santo.

60. Cargos de la jerarquía turca del país. Ver una excelente introducción a las estructuras políticas turco-otomanas en Tunicia en la primera mitad del siglo XVII, en T. B AC HROUCH, Formation Sociale Barbaresque et Pouvoir à Tunis au XVIIe Siècle, Túnez, 1977.

61. Región del noreste y sur de la capital, Túnez.

62. Hizb, propiamente “ grupo religioso”, actualmente “ partido político”.

63. Naq $\mathfrak{I} b$, “delegado”, con diversas acepciones polít i co-religiosas, entre otras «jefe de las clases de los jerifes o descendientes del Profeta», según Julio CoRTÉs, Diccionario de árabe culto moderno. Árabe - español, Madrid, ed. Gredos, 1996, p. 1.163.

64. Fuqar $\bar{a}$ ‘, “ pobres, faquires”, los miembros de su cofradía. 
Le daba una bandera verde ${ }^{65}$. Les encargaba que obedecieran a Dios -iensalzado sea!- y que obedecieran a su delegado, que era la autoridad superior que ellos tenían. Les decía:

«iPobres y devotos míos!

¡Que Dios Santo sea el centro de vuestra religión!

iEsforzaos en recordar continuamente el nombre de Dios ${ }^{66}$ y en obedecer a vuestra autoridad superior! ${ }^{67}$

¡Sed como hermanos que lo comparten todo!».

Los andalusíes obedecían y estaban siempre sumisos al Jeque -¡Dios, ensalzado sea, esté satisfecho de él!-, siempre atentos a lo que decía y obedientes a su mandato. Él -¡Dios esté satisfecho de él!- les favorecía siempre, les ayudaba y se ocupaba de ellos, mantenía correspondencia con ellos y aceptaba sus propuestas, decidiendo en su favor en todos los asuntos en los que tenían necesidad de él.

De todos los andalusíes el que más próximo estaba de él era el ya difunto Sīdī Muhamad Ibn-Abdi-r-Rafī‘ Al-Andalus $\overline{1}-¡$ Dios esté satisfecho de él!-68.

Cuando se fueron multiplicando los grupos de los andalusíes, surgió un hombre malo, que tenía por nombre 'Alī $\underline{\text { Tabit' }}$ - ¡Dios no le mantenga firme, ni por prestigio, ni por

65. Recuérdese que el verde es el color emblemático del islam, con lo que ese cargo o encargo administrativo está cargado de espiritualidad. Según otras fuentes, la bandera tenía una inscripción, con la profesión de fe en el islam y en el papel religioso de Sidi Bulgaiz (Ver T. BAchrouch, Le Saint et le Prince..., 112, 117). Sus biógrafos mencionan la importancia que daba al color verde, tanto en sus vestidos personales como en los regalos que hacía a las autoridades (ibid., 109, 117).

66. F F F

67. Fî̀t à'at al-muqaddam.

68. Ver datos sobre la biografía y los escritos de este andalusí, escritor bilingüe, en A.-H. GAFSI SLAMA, «Aproximación al estudio de los textos en árabe de los moriscos andalusíes en Tunisia», Sharq Al-Ándalus. Estudios Mudéjares y Moriscos, Teruel-Alicante, 12, 1995, 413-428 (especialmente, pp. 421-423), y Abdelmajid TuRKI, «Documents sur le dernier exode des Andalous vers la Tunisie», en M. de EpalzA - R. PetIT, o. c., pp. 114-125. Sobre la corres pondencia de Sidi Bulgayz con el propio Ibn-Abī-r-Rafí', dice éste: «[la expulsión de España y la acogida en el Imperio Otomano] Es una victoria debida al valor, a la excelencia y a la bendición de esta comunidad pura de los Andalusíes, de la que nuestro maestro, el eminente profesor y benefactor Sīdī Abū al-Gayıt al-Qaššāš [...] hablaba en algunas de sus cartas que me envió sobre ese tema, cuando ellos llegaron a estas tierras -¡Dios las mantenga en el Islam!-» (o. c., p. 121).

69. Importante personaje tunecino, muerto en 1631, fundador de la mezquita Harmel, que se conserva aún en la calle de los Tintoreros ( $a s$-sabbāg $\bar{I}$ ), en Túnez. Fue biografiado por el historiador de fines del sigloo XVII

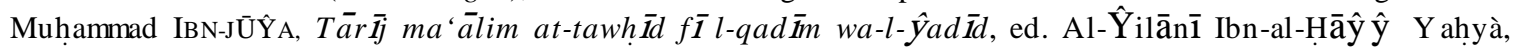
Beirut, edit. Dār al-‘ Arab̄̄î̀-l-Islāmī, 1385H, p. 243. 
mérito! ${ }^{70}$-. Dijo a los turcos:

«Este Abū-l-Gayt crea comunidades, de los andalusíes con pobres devotos. Indudablemente está proyectando y preparando algo».

Pero ellos no hacían caso de lo que iba diciendo. Entonces él escribió una misiva en la que decía:

«A todos los miembros del Consejo de Gobierno, de Túnez, a quienes Dios ha hecho vencedores ${ }^{71}$.

De Abū-l-Gayt Al-Qaššã̌, ¿acaso sabéis vosotros lo que proyecta y lo que va preparando?

Él ha formado un colectivo especial con los andalusíes en cada pueblo. Lo que quiere es alzarse con ellos contra vosotros. Os pasará por las armas, hasta el último de vosotros».

Después, echó la misiva, de noche, en la Casa del Consejo de Gobierno ${ }^{72}$. Cuando los turcos encontraron la misiva que él había lanzado, la leyeron y comprendieron la importancia de su contenido. Entonces dijeron:

«Llevadla a la superioridad y hacédsela leer al jefe supremo de todos vosotros, que es Yúsuf Dey».

Éste era el jefe de todo el Consejo de Gobierno ${ }^{73}$. Cuando se la llevaron y se la dieron a leer, éste les preguntó:

«¿Acaso reconocéis la letra de esta misiva, quién la ha escrito?».

Ellos le contestaron: «No, no la conocemos».

A continuación él les dijo:

«i Vosotros, todos los del Consejo de Gobierno y militares, que tenéis cada uno tres

70. Juegos de palabra con el nombre de ese todopoderoso ministro tunecino de las autoridades turcas: $\underline{t} \bar{a} b i t$, “ el que está firme, afianzado por Dios”. Fue uno de los pers onajes más importantes de la sociedad civil de Túnez en el primer tercio del siglo XVII, más “laico” que el piadoso jefe de cofradía Abū-l-Gay_t. También disponía de grandes sumas de dinero, provenientes especialmente del comercio portuario y no de las fundaciones piadosas basadas en los réditos de bienes inmuebles (campos, tiendas, casas...) cuyo administrador Abū-l-Gayt.

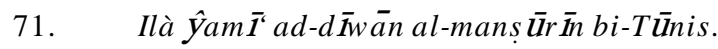

72. Där ad-Dīwān.

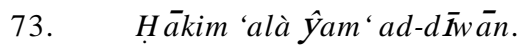


o diez fincas $^{74}$ !

¿Hay acaso alguno de vosotros que haya construido una mezquita, o que haya vestido al desnudo, o haya dado de beber al sediento, o haya hecho salir de la cautividad a un prisionero de los cristianos o le haya rescatado con su dinero?»

Le contestaron: «No».

Les dijo entonces:

«Pues el Jeque Sìdī Abū-l-Gayt _- Dios le dé bendiciones y toda clase de bienes!- ha hecho que se libere el cautivo y que sea redimido, y ha dado de comer a los pobres devotos y a los menesterosos. Ha reconstruido mezquitas que estaban en ruinas y ha defendido lugares de entradas que vosotros no podíais defender.

¿Y vosotros vais a aceptar la opinión de ese malvado que ha escrito esta misiva llena de falsedades?

¡Yo no me creo de todo eso ni una sola palabra!».

Cogió entonces la misiva y la hizo pedazos.

Después, cuando nuestro señor el Jeque tuvo noticia de todo esto, aumentó más todavía los gastos en provisiones y alimentos para el combate por la causa de Dios. Para nada tuvo en cuenta ni una línea de ese escrito, ni para disminuir y ni siquera para mantener el mismo nivel de esas cantidades. Dijo:

«Cada cual, pobres y devotos míos, encuentra el premio de lo que ha hecho».

El turco Yúsuf Dey ${ }^{75}$ vino a visitar al Jeque, que se alegró por ello. Le dijo a continuación:

«iSeñor mío! Implorad para mí cualquier cosa buena, ya que soy vuestro fiel servidor».

El Jeque imploró para él la bendición y suerte divinas. Estuvo muy satisfecho con él hasta que se marchó. Aquello fue una bendición eficaz por parte del Jeque ahora difunto -iDios esté satisfecho de él!-."”6.

De este primer texto del hagiógrafo Ibn-Abī-Lihya Al-Gafsī pueden deducirse ya unas

74. Hanšīr “ hacienda rural, heredad, estancia (Tun.)”, según J. CoRTÉs, o. c., p. 1.213, también “ finca, unidad de explotación, distrito agropecuario”, de propiedad estatal, encomendada a los jefes militares turcos de la regencia.

75. Yūsuf Dāy, Jefe del gobierno de Túnez, sucesor de Uzmán Dey a la muerte de éste, en 1610, gobernó la Regencia de Túnez hasta su muerte en 1637.

76. Traducción del texto árabe de la edición de L. AisSA - H. BOUJARRA, o. c., 138-141. 
confirmaciones de lo que se sabía y nuevas informaciones sobre la forma de inserción de los moriscos inmigrantes en la sociedad tunecina.

La primera confirmación es la del papel muy activo de Sidi Bulgayz en los primeros momentos de la llegada de la oleada de inmigrantes. Seguramente ya antes de que llegara el contingente may or en 1610, habría pactado con las autoridades turcas el acogerlos, sobre todo a los que habían pasado a Francia en tiempos del rey franco-navarro Enrique IV de Borbón (1589-1610) y que habían quedado bastante desamparados a la muerte del soberano francés. Las afirmaciones de que gastaba dinero, de los bienes que administraba, en rescatar y liberar a musulmanes ya señalan esa acción previa de atraer moriscos y otros inmigrantes al territorio de la Regencia de Túnez.

En el desamp aro de los primeros momentos de la llegada de los moriscos se le ve distribuir bienes de primera necesidad a los inmigrantes, especialmente alimentos (pan, sémola para el alcuzcuz, carne, leche) y vestidos. También se ocup a de su alojamiento, provisional en las familias y en los edificios públicos de la capital (como en el mausoleo de Sīdī Az-Zallīîy $\overline{1}^{77}$ ) y más estable en barrios de la capital y en diversas zonas agropecuarias del país. El propio Ibn-Abdi-r-Rafī ‘ Al-Andalusī, amigo y cooperador de Sidi Bulgayz, como se ve en el texto de Ibn-Abī-Lihya Al-Gafsī, concluy e su capítulo sobre la expulsión de los moriscos y su instalación en Túnez con el siguiente elogio del jeque:

«Yo no he visto a nadie, entre sus predecesores y los que le han seguido -como si Dios le hubiera reservado para eso-, que manifestara tanto amor y benevolencia como nuestro jeque el profesor -iDios tenga misericordia de él!-, cuando la llegada de los andalusíes y su dispersión en las zāwiyas y las escuelas, por lo numerosos que eran. Él respondió a los que se quejaban a él a propósito de nuestros pobres hermanos ${ }^{78}$ :

«Si el edificio supiera quién le ha visitado, se alegraría y besaría la huella de sus pasos.

Se exclamaría con toda su fuerza:

¡Sed bienvenidos, gente generosa y noble!»

Había destinado fondos de su záwiya -iDios la conserve, con todos los congregados, hasta el día del Juicio Final!- para la compra de 1.500 raciones de pan y otros alimentos, para los andalusíes pobres. Pero no podemos extendernos más sobre lo que ha hecho este profesor - iDios tenga misericordia de él!--> ${ }^{79}$.

77. Ver Antonio Almagro Gorbea, «La Zauiya de Sidi Qasim en Túnez», Tres monumentos islámicos restaurados por España en el Mundo Árabe, Madrid, ed. Instituto de España, 1981, 91-131, láms. 25-37.

78. Especialmente del encargado o sacristán de la mezquita-mausoleo de Sīd $\overline{1}$ Abū-l-Q asim Al-Zallīŷ̀̄, que se quejaba de que los niños defecaban en el santuario y lo impurificaban, anécdota y reacción que se menciona también en otros textos, en árabe y en español, con la respuesta de Sidi Bulgaiz.

79. Traducción del árabe, en A. TuRKI, o. c., p. 123. 
El texto en castellano resume también la política del jeque en relación con los inmigrantes moriscos en el territorio tunecino:

«Allí nos recibieron Uzmán Day, rey de Túnez, de condición soberbia y para nosotros manso cordero, Citi Bulgaiz con su santidad, y la jente con su Yçlam; y todos procurando acomodarnos y regalándonos con grande amor y amistad. Uzmán Day quitó una costumbre que había de pagar cada bajel cien escudos por la entrada, fundado en que se animasen a traernos a esta çiudad» ${ }^{80}$.

A medio plazo, lo que promueve Sidi Bulgayz es la organización interna de los inmigrantes en colectividades estructuradas (los hizb, plural ahzab, “p artidos, grup os, colectividades, secciones”) en las diversas poblaciones o zonas del país (los balad). Puso a la cabeza de cada uno de esos grupos un jefe (el muqaddam o naqib), relacionado muy probablemente con su propia cofradía. También recibe y confirma en sus papeles de líderes generales de la comunidad andalusí a los principales personajes (kubarā' o akabir y mašà'ij), entre los que Ibn-Abī-Lihya destaca al noble cherife y letrado bilingüe Ibn-'Abdi-r-Rafī', en vez de mencionar a los grandes comerciantes, documentados por otras fuentes, que fueron “Šayj o jeque de los andalusíes” durante la primera mitad del siglo XVII: primero Luis Zapata, por lo menos entre 1612 y 1615 ${ }^{81}$, y más tarde Mustafà Ibn-'Abdi-l-‘Azīz de Cárdenas o Al-Qardanāš, por lo menos desde 1622 a $1653^{82}$. Este elemento religioso y marabútico del jeque y santón Sidi Bulgayz, en su acción en favor de los moriscos, no era muy conocido hasta ahora por los investigadores modernos, ni con esos detalles.

La política de Sidi Bulgay z de formar un grupo específico de musulmanes en Tunicia -los andalusíes-, diferente de los tunecinos de la capital y con autoridades propias, seguramente encuadrados por miembros de su propia cofradía, coincidía con la forma de gobernar de la administración turca en el amplio Imperio Turco-Otomano, donde una minoría militar dominaba millones de habitantes de los países de ese Imperio gracias a una fragmentación y equilibrio de diversas etnias. Este sistema funcionaba bastante bien en Oriente Medio, por la tradicional fragmentación religiosa de los musulmanes (con diversas lenguas de los sunníes, con diversos grupos chiíes, con drusos, jarichíes, etc.), de los cristianos (melkitas, maronitas, coptos, armenios, sirios, caldeos, etc.), de judíos, de comerciantes europeos (mediterráneos, eslavos...), etc. En el Magreb, con una sociedad bastante homogénea, no era fácil organizar esa forma de comunidades étnico-religiosas. Las autoridades turcas del siglo XVI lo intentaron. La división étnica que refleja

80. J. Oliver Asín, o. c., pp. 410-411.

81. Ver M. de EpalzA, «Moriscos y Andalusíes en Túnez en el siglo XVII», Al-Andalus, Madrid, XXXIV, 1969, 247-327 (especialmente 288-292) [traducción francesa, sin el apéndice documental, en M. de EPALZA - R. PETIT, o. c., 150-186 (en especial, 175-176)].

82. Ver M. de Epalza, o. c., 288-292; M. de Epalza - R. PetT, o. c., 177-181 y passim; John Derek Latham, «Muçt’afa de Cardenas et l' apport des “Morisques” à la société tunisienne du XVIIe siècle», en Les Africains, París, 1976, vol. VII, 201-229 [ reproducido en S.-M. ZBISs - A.-H. G Afsi - M. Boughanmi - M. de EpalzA (edits.), Études sur les Morisque Andalous, Túnez, 1983, 157-178. 
en Argel el bien informado texto del pseudo-Haedo (Diego de Haedo, en realidad Antonio de Sosa), hacia 1580, correspondía a esa política de división social, que intentaron propiciar las autoridades turcas en sus dominios magrebíes ${ }^{83}$.

En la Tunicia de Uzmán Dey (1598-1610) la y a mencionada división de los magrebíes entre “capitalinos” y "provincianos”, queda bien reflejada en este texto por la oposición entre "Alī Tāâit Ibn-Šannūf y Sīdī Abū-l-Gayt Al-Qaššǎš, el uno comerciante-corsario y el otro religioso-administrador de propiedades inmobiliarias, esp ecialmente rurales. Éste intentaba aglutinar en su grupo a los andalusíes, muy diferentes de los tunecinos. De ahí su política de darles autoridades propias, fundidas con las de su propia cofradía, como le acusa claramente 'Alī Tāābit en el episodio de la carta al Consejo de Gobierno o dīwān militar de Túnez. El Presidente de ese Diwán (hakim 'alà ŷam' ad-dīwān) era Yúsuf Dey, que vemos enzarzando a los dos líderes tunecinos en sus disputas, aunque el texto de Ibn-Abī-Lihya le presenta como favorecedor de Al-Qaššăšs.

Pero tampoco hay que olvidar que la misma política de nombrar jefes autónomos y diferenciados para los andalusíes es la que revela el nombramiento de un "mutafarrique" andalusí, 'Alī Ibn-Muhammad El Mutafárrika, para los grupos de moriscos que el Sultán de Estambul instala en diversos poblamientos de Anatolia, en $1613^{84}$.

Por eso tiene su importancia este texto, no sólo por sus informaciones sobre la acción benéfica de Sidi Bulgayz, sino porque confirma también la política de las autoridades turcas de la regencia, provincia o vilayet de Túnez de fomentar la autonomía política de los andalusíes recién llegados, permitiéndoles el uso de su lengua propia, al menos en una primera etapa, y simultaneándola con el aprendizaje o mejor dominio del árabe y hasta del turco. El propio Yúsuf Dey evolucionará hacia el fomento de una mayor asimilación de los andalusíes en la sociedad árabe tunecina, por lo que algunos escritores moriscos -hasta en el siglo XVIII, los interlocutores de Francisco Ximénez ${ }^{85}$ - manifiestan cierta nostalgia del período de Uzmán Dey y Sidi Bulgayz, cuando les permitían más autonomía y un may or uso de la lengua española como signo de identidad.

83. Ver edición de Diego de HAEDo, Topografía e Historia General de Argel, Madrid, 1927ss. Análisis sobre la autoría de la obra, por G. CAMAMIS, Estudios sobre el cautiverio en el Siglo de Oro, Madrid, 1977. Aplicación a los moriscos-andalusíes de la descripción de Haedo-Sousa de los grupos sociales en la Argelia otomana del siglo XVI, con reproducción de los textos de Antonio de Sousa, en M de EpALzA, «Moriscos contra Carlos V: Argel y el modelo de inserción de los musulmanes hispanos en el Magreb (1516-1541)», en José MARTínEz Millán (dir.), Carlos V y la quiebra del humanismo político en Europa (1529-1558), Madrid, 2001, vol. V, 447-467, y «Papel político de los moriscos en el nacimiento de la Argelia moderna en tiempos de Carlos V», en M. J. RubieRa MATA (dir.), Carlos V, los moriscos y el Islam, Madrid, 2001, 201-232.

84. Ver el “documento Temimi 1613”, estudiado con esta problemática por M. de EpALzA, «Instalación de moriscos...»

85. Ver más adelante en este trabajo y M. de EpalzA, «Nuevos documentos sobre descendientes de moriscos en Túnez en el siglo XVIII», Studia historica et philologica in honorem M. Batllori (Anexos de Pliegos de Cordel, III), Roma, 1984, 195-228 [traducción francesa “Nouveaux documents sur les Andalous en Tunisie au début du XVIIIe siècle”, Revue d'Histoire Maghrébine, Túnez, 17-18, 1980, 79-108 (resumen en árabe, pp. 137-140), y en S.-M. ZBiss - A.-H. GAFSI - M. BoughanMi - M. de EpalZA, o. c., 57-90]. 
Más adelante, el texto italiano de Marcello Attardo ${ }^{86}$ permitirá matizar, ya al final de la tercera década del XVII, la política de diferenciación de los inmigrantes moriscos o andalusía con respecto a los árabes tunecinos, tanto de las ciudades costeras y sus alrededores (los "baldis" o ciudadanos) como de las llanuras y montañas del interior (los “alarbes” o a ' $r a b$ ).

También es notable la aplicación que hace Sidi Bulgayz a los inmigrantes moriscos de los conocidísimos versos del místico sevillano y patrón de Tremecén Abū-Madyān Šu’ayb, que hemos traducido del árabe ${ }^{87}$ :

«Todo territorio en el que os instaléis se felicitará, porque sois como la lluvia que ensombrece la tierra.

La gente que os vea os esperará con mirada favorable, porque ellos os verán como cimas de la humanidad.

Si vino una caravana para liberar la tierra vuestra, es como un perfume que atrae el caminar del pueblo.

Dios no prive a mi mirada de ver vuestra belleza, vosotros que mencionáis siempre a Dios, en el fondo de vuestras entrañas y de vuestro corazón.».

Estos versos tienen al menos cuatro niveles de lectura, que podrían exigir cuatro formas de traducción:

1. Canción de acogida de peregrinos. Es posiblemente la base tradicional, no documentada aún, de un canto que entonarían los peregrinos al llegar a la meta de la peregrinación o a cada final de etapa del viaje. Es una canción de bienvenida, entonada por los viajeros, que esperan una buena acogida por parte de la población de esa etapa, y por los propios habitantes de la ciudad santa de La М есa, para manifestar sus sentimientos de hospitalidad hacia los peregrinos que iban a hospedarse entre ellos. Hay que recordar que la sociedad musulmana es enormemente viajera y que el islam tiene la Peregrinación a La Meca (en su forma de hâŷy, una vez al año, y de 'umra, en cualquier época del año), como uno de los “cinco pilares del islam” (arkān al-islam), el $5^{\circ}$ de sus preceptos fundamentales, además de otras p eregrinaciones de devoción, no obligatorias, como las que aparecen en el tercer texto que traducimos en este estudio (la ziyâra), y otros muchos desplazamientos de tipo comercial, militar, etc.

2. Poema místico de Sīdī Abū-Madyān de Tremecén. Esta pieza, reproducida

86. Ver apartado 4 de este artículo: SEGUNDO TEXTO EN ITALIANO (SECRETARIO-ESClAVO ATtARDO, 1622).

87. Ver original árabe en L. Aissa - H. BoujARra, o. c., 138-139. Sobre este místico andalusí, nacido cerca de Sevilla y muerto en Tremecén (1126-1197), ver Georges MARÇAIS, «Abū Madyan», Encycl o pédie de l'Islam, $2^{\mathrm{a}}$ ed., 1960, I, 141-142. 
en la biografía de Al-Qaššāš por su discípulo Ibn-Abī-Lihy a Al-Gafsī, es uno de los textos religiosos más tradicionales de la mística musulmana (sufismo o tasawwuf) en el Maghreb ${ }^{88}$. Es el texto de peregrinación ap licado "a lo divino" al viaje del alma devota hacia la divinidad. Émile Dermenghem lo ha traducido al francés según esa interpretación mística de los temas básicos de la peregrinación que se encontraban ya en la canción original: bendición para los que acogen a los peregrinos, dignidad de esos viajeros, ligera nostalgia de la patria perdida, obligación de recordar las finalidades espirituales del viaje, etc.

3. Aplicación de la canción de viaje y acogida a los exiliados de España al llegar a Túnez. Es un texto precioso, político, para exhortar a los tunecinos a que reciban bien a los moriscos expulsados de España en razón de su fe, que llegan a su nueva patria musulmana, para la que serán una bendición. El texto corresponde bien con el ambiente de cofradías en el que se movía el patrón de esos moriscos Sidi Bulgayz. Éste fue seguramente el que hizo la aplicación del p oema a los exiliados moriscos, como relata su discípulo Ibn-Abī-Lihya, o fue éste último el que hizo la aplicación y se lo atribuyó al Jeque. De todas formas, el texto corresponde bien a ese ambiente piadoso marabútico, tanto por el tema básico de la peregrinación devota como por la hospitalidad de las cofradías o la piedad alrededor de la mención continua de los "hermosos nombres de Dios" (asmà Al-lah al-husnà).

4. Aplicación a los viajeros de todos los tiempos, en especial a los emigrantes modernos del siglo XXI. Puede ser un texto emblemático, en clave musulmana y de espiritualidad (también cristiana y humanística en general), para las continuas migraciones contemp oráneas, especialmente de los africanos y sudamericanos a España y a toda Europa.

\section{SEGUNDO TEXTO EN ÁRABE (HAGIÓGRAFO IBN-ABĪ-LIHYA, 1622)}

El segundo texto de Ibn-Abī-Lihy a Al-Gafsī, al final del mismo libro, y a forma parte de una “visión” mística o relato imaginario (ru’ya), también favorecedora de la imagen de Sīdī Abū-l-Gay $\underline{t}$ Al-Qaššāšs. Sin referirse explícitamente a los moriscos expulsados de España, presenta a unos nobles y piadosos andalusíes -granadinos, de la capital o reino de Granada, o por lo menos de la Corona de Castilla ${ }^{89}$ - que están de paso por el sur de Tunicia (por la ciudad de Gafsa, patria de Ibn-Abī-Lihy a Al-Gafsī o “de Gafsa”) y que conocen “las virtudes y méritos” del jefe de la cofradía. La anécdota puede fecharse de fines del XVI o primera década del XVII, cuando Ibn-Abī-Lihy a Al-Gafsī era relativamente joven todavía y vivía en su ciudad natal, antes de trasladarse a la capital,

88. Ver su estudio y versión en francés en uno de los libros pioneros sobre la mística popular árabe, en el capítulo consagrado al santo musulmán de Tremecén, en Dermenghem(s.a.:-).

89. Ver explicación de la tradicional división de los andalusíes en el Magreb, en el XVI-XVII, entre “granadinos” de la Corona de Castilla y “tagarenos” de la Corona de Aragón, en M. de EpalzA, Los moriscos antes..., pp. 11-18, 133-134, 226. 
Túnez $^{90}$. La anécdota o relato de esta visión onírica contribuye a exaltar la figura de Sidi Bulgayz. Este segundo texto es también interesante porque los granadinos manifiestan que llevan apellidos castellanos (“aljamiados, no-árabes”), uno de los signos de identidad más específicos de los andalusíes tunecinos, hasta nuestros días. Por eso sededica a esos hispanismos onomásticos unos particulares estudios, cuando se investiga sobre la lengua de los mudéjares, de los moriscos y de sus descendientes andalusíes en el mundo árabe e islámico ${ }^{91}$.

Nótese también el carácter onírico del relato, acentuado con las descripciones de la vestimenta de los granadinos, el hecho de que la escritura de los nombres aljamiados de los granadinos no queden escritos en la columna de tronco de palmera y que éste esté en el centro del patio y no en el bosque de columnas de la mezquita como es costumbre, y, sobre todo, en el desenlace del sueño, que deja nostalgia y mal sabor de boca en el narrador, que había tenido esas revelaciones extraordinarias en su sueño.

Aunque el relato del sueño de los andalusíes y su relación con Sidi Bulgay z parece, a primera vista, un elemento más en el panegírico hagiográfico del personaje recién fallecido, no hay que excluir que sea una toma de posición clara de su sucesor en favor de las buenas relaciones de tunecinos y andalusíes, cuyos intereses -políticos y económicos- estaban íntimamente implicados, en la red de las estructuras de la cofradía del jeque.

\section{CAPÍTULO 45}

En el que se mencionan anécdotas detalladas sobre las virtudes y méritos del difunto -iDios esté satisfecho de él!-.

Cuenta el autor de este texto, el siervo de Dios y pobre devoto, que cuenta con la ayuda de Dios - iensalzado sea!-- ${ }^{92}$ :

Cierta noche estaba yo durmiendo -ialabado sea Dios, El Viviente, que nunca duerme! $!^{93}$ cuando tuve esta visión, en vida del Jeque ${ }^{94}$-iDios esté satisfecho de él!-. Vi en sueños que yo

90. Para la identificación de los lugares y de los restos actuales de los edificios citados, ver Francesca Soro - P. de Montaner (coords.), Gafsa: une médina oasienne en Tunisie, Palma de Mallorca, Ajuntament de Palma-Commune di Alessandria, 1998.

91. Ver en particular M. de Epalza - A.-H. Gafsi Slama. «Léxico y onomástica hispánicos de los moriscos, conservados en Tunicia», VII Simposio Internacional de Mudejarismo. Actas, Teruel, 1999, 633-641, y El español hablado en Túnez por los moriscos y sus descendientes. Siglos XVII-XVIII. (Material léxico y onomástico documentado, siglos XVII-XX), II ${ }^{\mathrm{a}}$ parte, cap. 2 (en prensa).

92. Fórmula tradicional con la que el autor del texto se designa a sí mismo: Al-Muntașir Ibn-al-Murabit Ibn-Abī-Lihya Al-Gafs̄̄.

93. Expresión sacada del Corán, azora 2, aleya 255.

94. Sīdī Abū-l-Gay t Al-Qašš aš, jefe y director de la cofradía, fallecido en 1621-1622. 
estaba de pie en la Puerta de la Mezquita de las Purificaciones ${ }^{95}$, de Gafsa ${ }^{96}$.

Estaba yo con tres individuos que se aposentaban en el baño público (hammām) que estaba junto a la Puerta de la Mezquita de la Sala de Abluciones ${ }^{97}$. Me hice el encontradizo con ellos. Llevaban en los pies espuelas de montar. Les miraba atentamente y con extrañeza. Con ellos venían unos hombres vestidos con hábitos normales, como todo el mundo, salvo que cada uno de ellos llevaba un vestido blanco de lino y una aljuba de lana negra. Llevaban turbantes blancos. Cuando les vi me dije a mí mismo: «Éstos son morabitos ${ }^{98}$ ».

Me llamaron y yo besé sus manos. Eran dos hombres que iban detrás del que era su jefe religioso ${ }^{99}$. Él era Sīdī Ibrahīm Al-Garyān $\overline{1}^{100}$; los otros dos, no sé qué categoría tenían. Yo le dije a ese hombre que les encabezaba:

«Me permito preguntarte --ipor Dios, El Inmenso!- ¿de dónde sois?».

Contestaron: «Nosotros somos de Al-Ándalus y nuestra población de origen es Granada».

Me dije para mis adentros: «Éstos tienen que ser de noble familia granadina».

Y después les pregunté:

«Me permito preguntarte-ipor Dios, El Inmenso!- ¿cuáles son vuestros nombres?». Ellos me dijeron entonces:

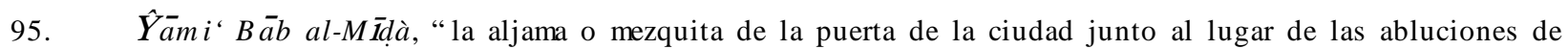
purificación previas a la oración”. "Que está junto al gran río o corriente de agua», según los editores L. AIsSA - H.Boujarra, o. c., p. 498. Según información del Dr. A.-H. Slama Gafsi, es el nombre antiguo de la Mezquita Mayor o “mezquita aljama”, estudiada en el mencionado libro de F. Soro - P. de Montaner, Gafsa:..., pp. 23 (n. ${ }^{0}$ 69), 160 (n. $\left.{ }^{\circ} 115\right), 322$; la mī dè o “ fuente de las abluciones” se encuentra en la o. c., en el plano de la p. 326 (n. ${ }^{\circ}$ ) y también en la p. 21 . El “Gran Río” mencionado por los editores tunecinos modernos (al-wād $\overline{1}$ $a l-k a b \bar{I}$ ) se estudia en la o. c., pp. 23 (n. $\left.{ }^{\circ} 66\right), 160$ (n. $\left.{ }^{\circ} 103\right)$ y 302, y especialamente en la fig. 461, donde se menciona el nombre de la mezquita en la calle «Rue Djemaa Kebir», con las fuentes “ de nuestro señor (¿el santo?)” ('ayn sayyidi-n $\bar{a}$ ) y “ de los acequieros” ('ayn as-saqqāy $\bar{n}$ ).

96. Ciudad caravanera, con importantes ruinas romanas, en un oasis pre-sahariano al sur de Túnez.

97. Al-Mìdà. Hay que recordar el tradicional uso nocturno de los hammäm o baños musulmanes como posada para los viajeros, que aprovechan de las estancias calientes, que conservan durante la noche cierta tibieza, aunque no funcionen las instalaciones de vapor y agua caliente de las horas diurnas de baño.

98. Mur ābit $\overline{\mathrm{In}}$, «min al-awliyā, gente piadosa y santa, santos», comentan los editores.

99. Im ämu-hum, “su imam”.

100. El Dr. Slama Gafsi me indica el parentesco de este personaje con otros miembros de su familia y de su poderosa cofradía, instalada ya en Kairuán, capital espiritual de la región: «Aḥmad Al-Gary ān̄ fue el maestro de Aḥmad

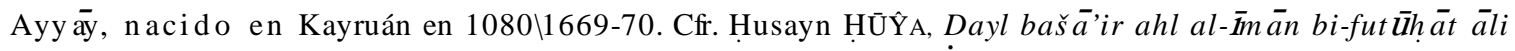
'U țmān (m. 1732), ed. Tāhịir Ma‘mūrī, Túnez, Ad-D ār al-'Arabiyya li-l-Kit āb, 1375/1955, p. 123. Hasta

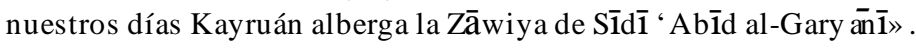


«Te vamos a poner nuestros nombres por escrito, porque nosotros sólo sabemos nuestros nombres en la lengua de los cristianos $^{101} \gg$.

Yo dije entonces: «Escribid».

En el patio de la mezquita había un tronco de palmera datilera que se alzaba como una columna ${ }^{102}$. Entonces aquel hombre, su imam, con ellos tras él, tomó una pluma y líquido químico de un tintero, mojó la pluma en el tintero y escribió en el tronco. Pero la pluma no mostraba nada, ni él marcaba con la pluma marca alguna. Yo miré lo pintado por si era en lengua de los cristianos $^{103}$, pero no aparecía ni una sola letra.

Le dije entonces:

«Me he dirigido a ti-ipor Dios, El Inmenso!- para que me informéis sobre el Jeque Al-Qaššă y sobre el grado de santidad que ostenta en esta época».

Dijeron entonces:

«No te lo diremos hasta que no nos prometas que no se te escapará nada de este secreto».

Yo les dije:

«iPor la obligación que tengo en ello, no se me escapará el secreto!».

Dijo entonces el imam:

«Él, en este tiempo, está al mismo nivel que Sīdī 'is̀̀ Ad-D ūnaydunī. Y tú guarda oculto este asunto; que quede entre nosotros».

\section{Contestaron:}

Entonces yo les pregunté: “¿A dónde os dirigís?».

«Hemos venido a realizar unas visitas religiosas ${ }^{104} »$.

Les dije entonces:

«Haremos juntos las visitas, con vosotros».

Ellos dijeron: «iQue sea bajo la bendición de Dios!».

A continuación hicieron una parada, de pie, en la puerta de la mezquita, y alzaron sus cabezas y sus manos, en la mezquita, rezando. Yo alcé mis manos con ellos. Juntos rezamos la Fátiha $^{105}$.

101. R Rūmīde España, s $\bar{u} r a$ o s $\bar{u} r \overline{1}$, según las variantes de las ediciones.

102. S șāriya rutaba, «wāqifa, alzada», añaden los editores.

103. Bi-r-r $\bar{u} m \overline{1}$.

104. Ziyāra, “visita piadosa, peregrinación, romería particular”.

105. El primer capítulo del Corán, oración habitual y fundamental de la liturgia musulmana. 
Ellos salieron y yo les seguía. Hicieron una parada de pie en la puerta de la Escuela de An-Nawarr $\bar{i}^{06}$. Se pararon a la entrada y recitaron la Fátiha. Yo la recité con ellos.

Después se dirigieron hacia Sīdī 'Alī Az-Zartīi ${ }^{17}$, y yo iba tras ellos. Nos cruzamos con un grupo donde vi a algunos pobres devotos de mi cofradía. Quise entonces informarles sobre esas personalidades, para que también hicieran la romería con ellos. Pero me contuve, de acuerdo con el pacto que había hecho de que no diría a nadie quiénes eran. Me contenté con hacerles una señal, un guiño, acerca de ellos, pero nadie supo nada por mí sobre quiénes eran.

Después ellos siguieron y yo iba detrás de ellos. Cuando llegaron a la puerta del jeque Sīdī 'Alī Az-Zartīiog, yo me adelanté a ellos y entré en la casa del jeque. Encontré a su hijo, Sìdī Muhammad Ibn-'Alī Az-Zartī, que cardaba felpa ${ }^{109}$ en la zāwiya ${ }^{110}$ y hacía mucho polvo. Volví a donde ellos estaban y les encontré de pie, fuera de la puerta. Les informé de qué había encontrado que hacía el hijo del jeque y les dije:

«Entrad y visitémosle. Vayamos luego a la Mezquita Mayor».

Ellos me dijeron entonces:

«Visítale tú por tu cuenta y nosotros le visitaremos por nuestra cuenta, porque nosotros no somos iguales que tú y tú no eres igual que nosotros».

Entonces desperté de mi sueño. Me puse a llorar de pena por la añoranza que me entró de ellos -iDios esté satisfecho de ellos!-. Recité entonces el poema siguiente: [...]» ${ }^{111}$.

106. «Vecina del río y enfrente de la mezquita de las Purificaciones», según los editores L. AISSA - H. BoujARRA, o. c., 499. El Dr. A.-H. Slama Gafsi me informa que la Mádrasa o Escuela de An-Naw arī es el actual Mausoleo de Sīdī Ismāīil. Ver F. Soro - P. de Montaner, o. c., pp. 22 (n. ㅇ 62), 160 (n. ${ }^{\circ}$ 105), 311. Ese mausoleo se llamaba también Madrasat al-Bāy.

107. Actualmente, también según el Dr. Slama Gafsi, es la mezquita Sīd $\overline{1}$ 'Alī Az-Zartīe, mencionada en el mapa de F. Soro - P. de Montaner, o. c., pp. 22-23 (n. ${ }^{\circ}$ 68), 161 (n. ${ }^{\circ}$ 108), 314 (según otras fuentes «Al-Binzartī», “ el de Bizerta”, puerto al norte de Tunicia). En otros manuscritos, Sīd $\overline{1}$ ‘ Alī Ar-Razq⿳亠丷⿵冂.

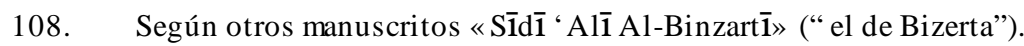

109. Al pie de la letra “ embellecía, arreglaba prendas de lana” (yu ýammilu), porque se sabe que Gafsa proporcionaba la lana de mejor calidad para prendas de lujo, como las chechías tunecinas, cuyo proceso de fabricación se iniciaba en esa ciudad y sus alrededores, antes de pasar a Túnez y a varios pueblos andalusíes del norte del país (El Alia, Tebourba, El Batán, Ariana...), a partir del siglo XVII. Ver M. de EpalzA - R. PetrT (edits.), o. c., 309, 318, 319, 321, 324, 332, 334. Era habitual en la Edad Media y casi hasta nuestros días que los sabios y piadosos musulmanes compaginaran sus actividades docentes, judiciales y religiosas en general con los oficios más rentables de terratenientes y jefes de negocios artesanales.

110. “Convento o lugar de encuentro religioso de musulmanes piados”.

111. O. ., pp. 498-500. 


\section{SEGUNDO TEXTO EN ITALIANO (SECRETARIO-ESCLAVO ATTARDO, 1628)}

Un cuarto texto, de 1628, prolonga el tema de la rivalidad entre 'Alī Tāait y Sidi Bulgay $\underline{t}$ a propósito de los andalusíes, pero seis años después de la muerte del santón protector de éstos. Al menos así ha sido presentado por varios historiadores modernos, interpretando en este sentido las menciones a las actuaciones del "moro" 'Alī Tābit y del “andalusí” Mustafá de Cárdenas (Al-Qardanã̌s) en la guerra que enfrentó -por segunda vez, en 15 años - a tropas de la también regencia turco-otomana de Argel con sus vecinos orientales de Túnez, invadida por los argelinos. El análisis más det enido del informe en italiano de Marcello Attardo -esclavo y secretario del imp ortante personaje p olítico y militar Osta Murad Genovese, de origen cristiano pero integrado en el estamento supremo de los turcos que gobernaban la regencia- permite matizar y hasta casi calificar de inexistente el enfrentamiento de los dos líderes y de sus respectivas etnias, en una común causa frente a la invasión argelina.

La visión tradicional de los historiadores modernos, interpretando los textos históricos del siglos XVI -árabes e italiano- presentan al soberano tunecino Yúsuf Dey formando dos batallones contra los argelinos, cuando la invasión de Tunicia de 1628, uno de ellos al mando de 'Alī Tāābit con los árabes tunecinos y otro al mando de Mustafá de Cárdenas con sus andalusíes ${ }^{112}$. El texto italiano, tan original y detallado, ha sido generalmente interpretado por los historiadores (Roy, Pignon, Latham,...) como una prueba de que ambos comerciantes y líderes, el morisco-andalusí y el árabe-tunecino, llegaban a tener cada uno un ejército propio y diferente, que ponen a disposición de Yúsuf Dey, cuando se ve inminente la llegada de los invasores por las llanuras y el valle del río Medjerda, al oeste de la capital tunecina. Allí estaban instaladas algunas de las principales colonias agrícolas de los moriscos (Testur, Sluguía, Grish El Ued, Medjez El Bab, Teburba, Batan...), que otras fuentes más tardías dicen que fueron desalojadas por las autoridades tunecinas, ante la imp osibilidad de defenderlas contra los argelinos ${ }^{113}$.

112. Relato detallado del esclavo Marcello Attardo al comendador de la Orden de Malta Carlo Aldobrandini sobre este conflicto entre Argel y Túnez, resumido en francés y editado en su original italiano por Bernard Roy, «Deux documents inédits sur l’expédition algérienne de 1628 (1037 de l’Hég.) contre les Tunisiens», Revue Tunisienne, Túnez, n. ${ }^{\circ}$ 122, mayo 1917, 183-204, recogido por J. Pignon, «Une géographie de l’Espagne..., 74, y, luego, por John Derek Latham, «Muçt’afa de Cárdenas et l'apport des «Morisques» à la société tunisienne du XVIIe siècle», en Les Africains, Paris, vol. VIII, 1977, artículo reproducido en S.-M. ZBISS A.-H. Gafsi - M. Boughanmi - M. de Epalza, o. c., 158. Citaremos el texto italiano, con la lengua y la ortografía de la edición de Roy, explicando y explicitando sólo algunas nociones de los planteamientos políticos que nos parecen más importantes.

113. Ver M. de EpalzA, «Nuevos documentos...: «La Seluquía, una legua distante de Textor [...] Este lugar le reedificaron los moros andaluces cuando vinieron de España. En tiempos del BeySerife se despobló este lugar, porque este Bey, para que los argelinos que hacían la guerra no encontrasen quien los diese de comer, mandó que despoblasen todos los lugares y se viniesen a vivir a Túnez. Éstos lo hicieron así y despoblaron. Otros no lo quisieron ejecutar y les fue mejor. Por este motivo hay muchas casas caídas y lo mismo en el Bebo. Y al presente van reedificando algunas, y tendrá cincuenta vecinos y algunas mezquitas» [o. c., p. 218, cita sacada del Diario..., de Francisco Ximénez, 27 de julio de 1724), y «Llegamos al lugar de los Cathalares, que llaman Gressi Luat, el cual tendrá cien vecinos, muchas casas desabitadas y caídas, por haberlas dejado cuando el 
Sin excluir enteramente la existencia de esa realidad expuesta por historiadores actuales de la guerra entre Argelia y Túnez, el texto leído en su original parece limitar la oferta a la mera defensa de los puertos tunecinos (Bizerta, La Goleta...) frente a una invasión, desembarco u ocupación marítima por parte de las naves argelinas. Los dos líderes -y no sólo ellos- habrían disuadido o rechazado la ocup ación argelina de La Goleta, puerto marítimo de la laguna que separa Túnez-capital del mar (la gola o “garganta pequeña”), con un grupo más bien conyuntural de ciudadanos, organizados eso sí por Mustafá de Cárdenas y por 'Alī Tābit. No serían militares profesionales o regulares, sino una forma de "resistencia civil", a la vista de los fracasos de los ejércitos turcos del Bey en el campo de batalla de las llanuras que daban acceso terrestre desde la frontera a la capital y a los centros comerciales de Túnez así como por el desembarco de los argelinos y posterior quema de algunas propiedades tunecinas en el pueblo costero habitado por los andalusíes de Solimán, en la costa este y a pocos kilómetros de la capital ${ }^{114}$. El informe de Attardo relata brevemente este último episodio, del primer ataque de las naves argelinas que tiene un contexto social con importante impacto en Túnez: «... li tenanti di essi vasselli si sono raffrescati in un certo casale d'Andalusci che si chiama Solimano e ivi abrugiarno un gran massaria con un bel giardino del detto signor Ostamorato» ${ }^{115}$.

En efecto, los marinos de esas naves desembarcaron "en cierto pueblo de andalusíes que se llama Solimano y allí quemaron una gran finca del dicho señor Osta Murad”. Este pueblo (“casale”) era la próspera capital comarcal de una de las cinco zonas de asentamientos rurales de los moriscos en el país, en la vía que unía Túnez con la costa oriental de Tunicia, atravesando la península de Cap-Bon (Ras-Adar); la finca ("massaria”) era una importante propiedad de uno de los principales políticos y militares de la clase dirigente del país, yerno de Yúsuf Dey, que pocos años después asumiría el cargo sup remo de Bey del país, cabeza de una dinastía familiar que duraría siete décadas, hasta 1702. En esa misma zona encontramos el mismo binomio de unos poblados de colonización morisca-andalusí alrededor de la finca del potentado y jeque de los andalusíes Mustafá de Cárdenas, también amenazado, por tanto, por el ataque de los argelinos, que sabían muy bien el alcance político de su pequeño desembarque, como se verá más adelante.

El texto italiano especifica las disposiciones de las autoridades para defender su territorio y su capital, en espera de la expedición terrestre y marítima de los argelinos:

«E minutamente in tanto le spie devano li ragguagli di quanto seguiva cola all'illust. signor Bey e doana ${ }^{116}$ di Tunisi, e percio havendo nova giornalmente che le cose s'aumentavano a piu potere, si nego

Cherif mandó que se retirasen sus moradores a Túnez» [ibid., p. 219, a 29 de julio de 1724].

114. Ver resumen en francés de esos episodios en B. RoY, o. c., pp. 183-189.

115. B. RoY, o. c., p. 196.

116. En este contexto se trata del Diwan o Gobierno de la Regencia y no del diwan al-bahr, “aduana marítima”, que es el sentido comercial y económico más normal de la palabra italiana dogana, como de la española “aduana”. El Bey o “bey de campo” era el mencionado Murad Bey, que irá asumiendo paulatinamente funciones políticas cada vez más importantes, al lado del soberano el Dey Yú sef, suegro suyo, hasta tomar el poder y fundar una 
primieramente il porto alli corsari d'Algeri solito d'arsegli per l'addietro. E senz'altra dimora incominciorno a munire le fortezze, come Bizerta, La Guletta, Chef e molti altri dove stimavano di poder essere staneggiati, provedendoli di maggiore numero di soldati, artiglierie, biscotto, ed altrenecess.monitioni per diffendersi dal inimice, faciendose di piu, rassegnasarie d'armi distintamente da le contrade e Borghi della città di Tunisi...

[se enumeran los tres principales suburbios de Túnez con sus tropas, además de 700 genízaros, unos 2.500 zuavos, menos de 500 bombardieri con]

e le andalusse ancora, il caito delli quali ossia capo di giustizia che chiamano in lingua spagnuola Alcaide, si é offerto a la Doana di Tunisi di dargli in ogni evento 7.000 huomini d'arme ben armati» ${ }^{117}$.

De esta primera parte del informe de Attardo, sobre los preparativos ante el inminente ataque argelino, conviene analizar especialmente esta última frase, referente a los andalusíes y a su jefe. Sin nombrar personalmente a Mustafá de Cárdenas, como se hará más adelante, se le da el título de caito, “alcaide” -título militar-, pero se precisa que es "capo de giustizia”, es decir “alcalde” -título civil-, “que llaman en lengua española Alcaide”. Este equívoco o imprecisión del español, es un título que perdurará con otros en el castellano de los pueblos andalusíes, un siglo después, donde se conservaba el título en lengua española, según el viajero español Francisco Ximénez, en la pequeña capital comarcal de Testur: «...llegamos a Textor... Nos recibió el xeque o gobernador... El gobierno es de moros andaluces [“árabes andalusíes”]. Tienen un xieque, a quienes los mismos moros en español le llaman gobernador, dos regidores y un alguacil, a la manera de España... Porque el gobernador llaman alguacil y a los regidores, como se hace en España» ${ }^{118}$. Parecida ambigüedad entre el título militar del arabismo español “alcaide” (de al-qā‘id, “jefe, gobernador”) y el título judicial de "alcalde” (de al-qā̄ī, “juez, capo di giustizia”) se encontrará también en el cargo de "jeque de los andalusíes” de otro pueblo andalusí del siglo XVIII, Solimán; «El gobierno de la justicia es precisamente de los andaluces y se reduce a un gobernador oxieque, a tres jurados y tres alguaciles. El primero es elegido por voz de todos los moros que desciende la nación española...»" ${ }^{119}$. En todos los casos el "jeque” o xayj es un cargo civil o administrativo, relacionado esp ecialmente con la justicia y gobierno, que sólo excep cionalmente puede tener funciones militares.

Una vez derrotados los tunecinos, el informe de Attardo describe la desolación de la

dinastía que gobernaría entre 1637 a 1702, los Beyes Muradíes.

117. Ibid., p. 190 .

118. M. de Epalza, «Nuevos documentos sobre descendientes de moriscos en Túnez en el siglo XVIII», Studia historica et philologica in honorem M. Batllori (Anexos de Pliegos de Cordel, III), Roma, 1984, 195-228 [p. 219] [traducción francesa "Nouveaux documents sur les Andalous en Tunisie au début du XVIIIe siècle”, Revue d’Histoire Maghrébine, Túnez, 17-18, 1980, 79-108 (resumen en árabe, pp. 137-140), y en S.-M. ZBISS - A.-H. GAFSI - M. BOUGHANMI - M. de EPALZA, o. c., 57-90]

119. Del Diario de Francisco Ximénez (22-10-1724), ibid., p. 22. 
población de la capital, llorando sus muertos y desaparecidos. Ante la inminencia de la ocupación de la capital por los argelinos, vuelven a aparecer los andalusíes y su jefe, junto a su colega tunecino 'Alī Tābit:

«...e tali disgusti e pene s'aumendorno a maggior copia perque giovedi primo del mese de giugno a giorno chiaro son entrati nel porto ossia spiagia della Guletta 74 grossi vascelli d'Algiere per timore delli quali le signorj Ali Thebet moro e Mustafa di Cardines Amdalosso con alcuni altri delli maggiorj della Citta comandavano violentamente con le spade ignude alli cittadini di Tunisi che dovessero andare ben armati nella sudetta spiaggia per custodire la fortezza, con le marine, e impedir l'inimico non potersi raffrescare in terra, ne far dell'aqua e di subido seguj, mandandoli alternamente li campi, e cavallerie a tal effetto, essendo la suddetta fortezza discosta della citta di Tunisi 12 miglia e si siede il comandodi essa gente a Sidi Tunisi primo gianizzaro al quale spetta la dignita di bey...» ${ }^{120}$.

Esta segunda referencia al papel de los andalusíes en la guerra entre argelinos y tunecinos aporta algunas precisiones importantes, especialmente para matizar las relaciones entre 'Alī Tāaibit y Mustafá de Cárdenas, a los pocos años del fallecimiento del protector de los moriscos Sidi Bulgayz.

Primero, muestra la base real de lo que los historiadores árabes, mencionados por Roy al inicio de su trabajo, resumirán décadas después como “doble jefatura” del árabe-tunecino ‘Alī Tābit (“moro”) y del morisco-andalusí Mustafá de Cárdenas (“andalusso”). Eran los personajes más conocidos entre los que arengaban a los ciudadanos de Túnez (“cittaddini di Tunisi”), arma en mano ("con le spade ignude"), pero no eran los únicos: había otros ciudadanos importantes de la ciudad (“con alcuni altri delli maggiori della Citta”).

Esta “improvisación” -muy explicable, por otra parte- indica que el anterior ofrecimiento general de los 7.000 andalusíes, cuando los ejércitos argelinos iban avanzando desde la frontera, no había tenido efecto en una estructura militar suficientemente preparada. Era una cifra seguramente abultada, contando con toda la población civil de origen andalusí en Túnez y sus alrededores que podían empuñar las armas. Esos andalusíes del jeque Mustafá de Cárdenas, como los árabes-tunecinos de 'Alī Tābit, no eran militares profesionales, como los cuerpos guerreros de la autoridad turca, sino civiles que podían ser armados: un puro deseo (“huomini d'arme ben armati”, “cittadini di Tunisi che dovessero andare ben armati”).

En realidad el movimiento que aparece en este texto era un impulso de los líderes de la burguesía capitalina, los mercaderes, cuando ven peligrar su centro comercial, el puerto de La Goleta, con sus playas o atracaderos para sus naves comerciales ("spiaggia”) y con el reducido castillo ("fortezza"), llamado "del Emp erador Carlos V”, que no estaba preparado para resistir a una flota como la argelina. Se quería evitar la instalación de la flota en la costa, esta vez mucho más peligrosa que la anterior escaramuza contra el pueblo de Solimán. A continuación se mencionará una situación semejante en el puerto y bahía de Bizerta, a unos 60 kms. al norte de Túnez. Y también los diversos navíos atracados frente a La Goleta, unos expoliados por los argelinos y otros que

120. B. RoY, o. c., p. 195. 
pudieron defenderse.

En realidad moros y andalussos ("essa gente", dice el informe) debían ir encuadrados por un militar profesional y no por sus dos o más “jefes étnicos”: el mencionado jenízaro con titulación general de "Señor de Túnez y primer jenízaro, con título de Bey" ("e si siede il comando di essa gente a Sidi Tunisi primo gianizzaro al quale spetta la dignita di bey”). Ostentaba este cargo de "Bey de Campo" precisamente el futuro soberano de Tunicia ya mencionado Osta Murad, el de la finca de Solimán.

Despojados del carácter excesivamente militar que los cronistas tunecinos del XVII y los historiadores del XX han dado a los dos personajes en la guerra entre Argel y Túnez, hay que suponer que la rivalidad entre Abū-l-Gay $\underline{t}$ y 'Alī Tạābit no debía tener la tensión bip olar que parece indicar el texto del hagiógrafo del santón Sidi Bulgayz. Latham advierte, en línea investigadora que habría que profundizar, cómo 'Alī Tābit y su cuñado Mamet Sitti se entenderán muy bien con el poderoso “alcaide de los andalusíes” Mustafá de Cárdenas, después de la muerte de Sidi Bulgayz, haciéndole partícipe de su poder e influencia económica y política, definidos por algunos contemporáneos como "señores de las aduanas de Túnez y de su reino” y "señores de los derechos y comercio de este reino" ${ }^{121}$.

\section{APÉNDICE FILOLÓGICO: ANÁLISIS SEMÁNTICO DEL NOMBRE DE SIDI BULGAYZ.}

También se puede analizar la personalidad de Sidi Bulgayz partiendo del punto de vista antrop onímico, de análisis de las partes de su nombre completo, que pueden presentarse de la forma siguiente:

sīd $\bar{i}$ ("mi Señor", título de respeto religioso, equivalente en castellano a "Reverendo, Monseñor, Venerable, Santo, San”).

Muhammad (Muhámmad, “el muy alabado”, nombre propio de persona, el principal de los nombres del Profeta del Islam (en español Mahoma ${ }^{122}$ ), muy utilizado por los musulmanes para sus hijos varones, en todas las ép ocas y en todas las clases sociales) ${ }^{123}$.

121. Ver J. D. LAtHAM, « Muct’afa de Cárdenas..., 1977, pp. 317-318; 1983, p. 168.

122. Para la relación filológica, etimológica y religiosa entre Muhámmad (en árabe) y Mahoma en castellano (como también en otras lenguas románicas), se puede ver el estudio monográfico «1.5 Sobre la dualitat de noms referits al profeta de l'islam en català: Mahoma, Muhàmmad», en M. de EPALzA (con Josep ForC ADELL y Joan M. PeruJo), L'Alcorà. Traducció de l'àrab al català, introducció a la lectura i cinc estudis alcorànics, Barcelona, ed. Proa, 2001, 2002, 1.008-1.013, y más resumido, en castellano, en el prólogo de la reproducción del artículo mencionado en la nota siguiente, ID., «Los nombres..., Verde Islam, Almodóvar del Río (Córdoba), 4/12, 1999, 24-26.

123. Ver un estudio detallado de un listado o letanía de los 200 nombres de Mahoma, a partir de un texto devocional marroquí del siglo XV, por M. de EpALZA, «Los no mbres del Profeta en la teología musulmana», Miscelánea Comillas. Revista de estudios históricos, Madrid, XXXIII/63, 1975, pp. 149-203, y la abundancia mayoritaria de este nombre entre los moriscos varones documentados en Túnez, con diversas grafías, en el capítulo $2 .^{\circ}$ de la 2. ${ }^{\text {p }}$ arte del libro de M. de Epalza - A.-H. Slama GAFSI, o. $c$. 
Abū l-Gayt (nombre de paternidad, "el padre de la lluvia abundante, el padre de Al-Gait, el generoso").

Al-Qaššaš (ap ellido profesional, seguramente heredado de sus antecesores o quizás de oficio ejercido por él mismo al mismo tiemp o que sus actividades religiosas y políticas: "el revendedor de ropa (vieja)”. Es el único sentido aplicado a una persona y no a objetos o acciones muy concretas por Dozy, en su obra en la que recoge numerosas citas de diversos autores, sobre derivados de la raíz q-š-šs ${ }^{124}$. Sus fuentes para este epíteto o nombre de oficio (al-qaššaš) son el Vocabulista in arabico de Pedro de Alcalá, de principios del XVI (en la voz latina supellectilis) y el historiador magrebí Al-Maqqarī, de principios del XVII, con la palabra árabe qaššaš, que traduce al francés «revendeur, frippier» ("revendedor”, “ropavejero”). Hay aún hoy un zoco importante del centro de la Medina de Túnez que lleva el nombre de esta profesión: Sūq al-qaššašinn. Aunque Dozy no recoge ningún texto con otros significados religiosos, como lo había hecho veinte años antes Kazimirski ${ }^{125}$, no se puede excluir que sea un título religioso del personaje, con esos sentidos de "hombre que vive de limosnas; de persona que se retira del trato normal de la gente para dedicarse a la devoción”. Julio Cortés, por su parte, no encuentra en el árabe moderno ninguna referencia a una actividad o cargo religioso ${ }^{126}$. Entre los autores de diccionarios árabes, Ibn Manzūr considera que quien «...recoge los desechos alimenticios y se alimenta de ellos, ése es el qaššaš [“ropavejero, remendón”] y el rammām [“restaurador, reparador de cosas podridas”] [...]; al-qašš come de lo que deja la gente sobre los estercoleros $[\ldots]{ }^{127}$.

Como nombre de oficio de una persona puede, por tanto, deducirse que este nombre indica una forma de ganarse la vida como artesano que remienda, compra y vende cosas viejas (nombre del propio Abū-l-Gayt o del antecesor del que hubiera heredado el apellido y/o el oficio), en el sentido que recoge el Diccionario de la Academia de la Lengua: «remendón, na. adj. Que tiene por

124. Ver R. P. Dozy, Supplément aux dictionnaires arabes, Leyden, ed. Brill, 1881 (reimpr. Beirut, 1968), II, pp. 355-356.

125. Ver A. DE BiBerstein KAZIMIRSKI, Dictionnaire arabe - français, Paris, ed. Maisonneuve, 1860, II, pp. 740 -741, que recoge los siguientes sentidos religiosos: «qašša [...] 5. Ramasser de tout côtés tout ce qui se trouve, $p$. ex. des morceaux jetés dans le fumier et s’en nourrir. De là 6. Vivre d'aumônes. [...qaššāša] Ramasser des morceaux jetés pour s’en nourrir [...aqšaša] 2. S’esquiver, se retirer avec précipitation. [...inqašaša] Se retirer avec précipitation. [...] qaššāš Qui ramasse partout de quoi manger, qui se nourrit de morceaux jetés au fumier, ou qui vit d’aumônes. [...] muqišš qui se retire en toute hâte, avec précipitation».

126. J. CoRtés, en su o. c., 903, no recoge este sentido religioso entre los nombres comunes derivados de la raíz q-š-š (verbos, nombres, adjetivos...) en época moderna, y prefiere, para esta palabra concreta en su forma de nombre de oficio (qašš $\bar{a}$ ), la acepción del dialectal egipcio actual «qaššāš, barrendero», que recoge los restos (de alimentos, suciedades, desechos...), y de ahí una clase de transportes públicos egipcios «tren ómnibus (Eg.)».

127. Ibn Manzūr, Lis ān al-‘arab (presentación por Abd-Allah Al-Ulaili; revisión de la edición del texto por Yúsuf Jayyat), Beirut, 1988, vol. 5, p. 32. 
oficio remendar. Dícese especialmente de los sastres y zapateros de viejo» ${ }^{128}$. Pero también puede ser un título piadoso, de actividad en una cofradía, como eran llamados Sidi Bulgayz y sus compañeros, faqīrr, "pobre”, según los dos sentidos religiosos que recoge Kasimirski.

En resumen, el análisis de los cuatro elementos que forman el nombre de ese personaje indican unos títulos o cualidades sociales que debió adquirir paulatinamente: el joven Muhmmad -nombre personal- pasó a ser un profesional Al-Qaššaš -trapero remendón- o un hombre religioso -que vive de lo que dan y se dedica especialmente a la piedad-, muy respetado y venerado por su cofradía con el apelativo de Sīdī, "Señor Mío, Monseñor”, que indica también su señorío y poder sobre hombres y bienes, y al que se atribuye cierta paternidad en el mote Abū-I-Gayt, "Padre de la Generosidad”, en los varios sentidos que puede tener este nombre en árabe ${ }^{129}$.

\section{CONCLUSIÓN}

Estas traducciones y estos estudios contrastados de cuatro textos, de entre 1609 y 1628 , sitúan, con anécdotas diversas, la personalidad social, política y religiosa de Sidi Bulgay z y las formas y motivaciones de su ayuda a los moriscos o andalusíes para que se instalaran en el territorio otomano de Túnez, encuadrados especialmente por su propia cofradía religiosa. Su acción, reflejada muy directa aunque sólo parcialmente por esos textos, viene enmarcada en un triple marco de restauración política del reino, regencia, vilayet o provincia de Túnez: en el nuevo marco del gobierno imperial turco-otomano, en el marco de la nostalgia histórica árabe medieval del reino hafsí de Túnez de antes de las ocupaciones española y maltesa del siglo XVI y en el marco de las organizaciones sociales ligadas a las cofradías religiosas de todo el Magreb islámico desde el siglo XV, muy bien representas por la cofradía qaššāiyya del jeque Sidi Bulgayz Al-Qaššǎš.

De hecho, el propio Murad Bey, cuando entra derrotado al interior de las murallas de la capital, se refugia en la tumba y con la cofradía de Sidi Bulgaiz ("si salvo nella seuia cioe luogo sacro restando ivy sepulto sidi Belgaed”, como resume en francés el hist oriador Roy. El texto italiano original concluye con esa noticia la descripción de la derrota tunecina: «s’impadronj dell'artigliaria del campo di Tunisi e li detti spai con la gran turba de villanj guadagnorno e sacchergiorno l'inimici padiglioni e nel medessimo instante incominciorno a dannegiarlo con li propij canonj al esercito di Tunisi, quale inteso e visto a Morato bey travestitosi in habito di villano insieme con il fillio qual stava con guardia di 400 huomini a cavallo a sue spese, abbandonando la

128. Diccionario de la lengua española. Real Academia Española, Madrid, 1992 (21. a ed.), II, p. 1.768

129. Sobre sus cinco hijos e hijas, 3 varones y 2 hembras, y su descendencia, ver T. BACHROUCH, Le Saint et le Prince..., pp. 116-121. Tuvo mucha importancia una de sus hijas, por haberse casado con el jefe y fundador de otra importante cofradía y haber acumulado así el poder espiritual, económico y social de las dos organizaciones religiosas, poder que perdurará durante los siglos siguientes, según el estudio de Mohamed El Aziz BEN Achour, «L'itinéraire d' une famille tunisienne d'origine andalouse: les Ibn 'Ashur (XVIIe-XXe ss)», en S.-M. ZBiss - A.-H. GAFSI - M. Boughanmi - M. de EpalzA, o. c., 15-34. En ambos estudios puede verse el sistema matrimonial por el que un rico jefe de cofradía como Sidi Abulgaiz casaba a una hija suya con otro jefe de cofradía, para unir a dos familias, dos patrimonios y dos herencias de poder religioso y de poder económico. 
caballeria con dire di voler salvar il denaro sudetto, si mese in fuga per oblique strade, e sotto di doi di giugno de notte entro sconosciuto in Tunisi e si salvo nella zeuia cioe luogo sacro restando ivy sepulto sidi Belgaed primo marabuto di questo regno...» [mientras que luchaban los ejército en Túnez y sus alrededores]. 187

\title{
RESUMEN
}

Los diversos textos del siglo XVII que hablan de Sidi Bulgayz y especialmente los tres nuevos y largos que se presentan en este trabajo enfocan mejor la personalidad pública del religioso tunecino, especialmente en el marco y motivaciones de su acción en favor de los musulmanes expulsados de Esp aña y acogidos en el territorio tunecino. Muestran en particular sus relaciones con diversos poderes sociales del país, a través de los textos contrastados y bastante detallados de diversos contemp oráneos suyos y de escritores que le conocieron directamente, en el momento de la llegada de las princip ales oleadas de inmigrantes moriscos, hacia 1610 (el capitán británico Eyllatt y su sucesor al frente de su cofradía Ibn-Abī-Lihya Al-Gafsī).

Palabras clave: Abū-l-Gayt , Al-Qaššāšs, cofradías, expulsión, Moriscos, Túnez

\begin{abstract}
The many 17th-century texts on Sidi Bulgayz and particularly the three news long ones presented in this book focus mainly on the public personality of this Tunisian muslim leader, and particularly on the framework and motivations for his actions in favor of the Muslims expelled from Spain and settling in Tunisia. They particularly show his relations with the different social powers of the country, through contrasted and quite detailed texts from contemporaries and writers who knew him personally, on the arrival of the first waves of Morisco immigrants, around 1610 (the British Captain Eyllat and the successor of Sidi Bulgayz at the head of his religious order and brotherhood Ibn-Abi-Lihy a Al-Gafsi).
\end{abstract}

Key words: Abū-l-Gayț, Al-Qaššāšs, brotherhoods, expelled, Moriscos, Tunisia 